
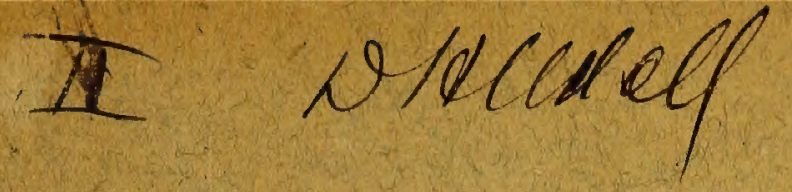

\title{
REPORT ON THE RESULTS OBTAINED BY THE SPECIAL COMMITTEE FOR THE INVESTIGATION OF INFECTIOUS ANEMIA AMONG HORSES.
}

THE HORSE ADMINISTRATION BUREAU.

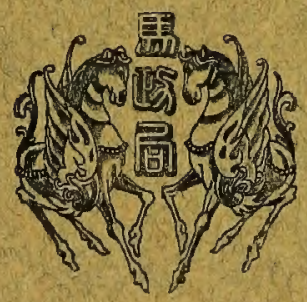




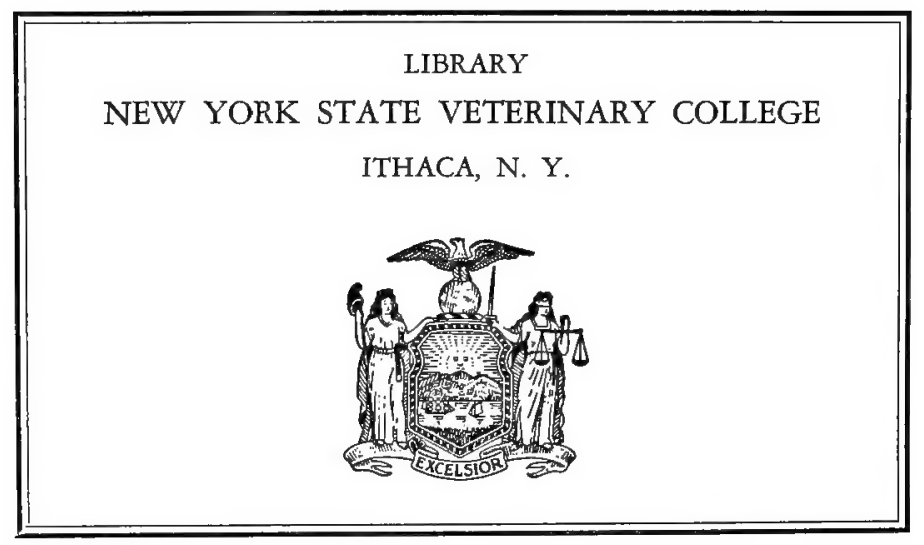




\section{SF 959.A5S74}

Cornell University Library

Report on the results obtained by the Sp

31924003333006

Date Due

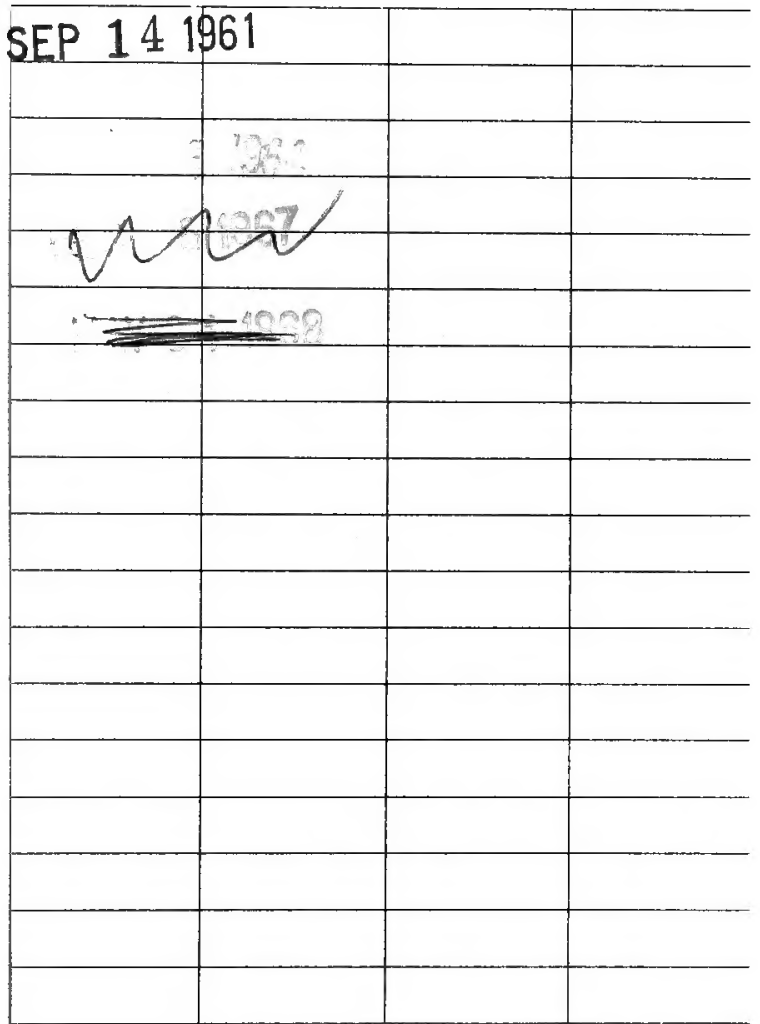

Library Bureau Cat. No. 1137 


\section{Cornell University Library}

The original of this book is in the Cornell University Library.

There are no known copyright restrictions in the United States on the use of the text. 


\section{REPORT ON THE RESULTS OBTAINED BY THE SPECIAL COMMITTEE FOR THE INVESTIGATION OF INFECTIOUS ANEMIA AMONG HORSES.}

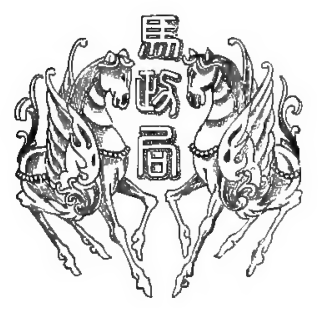

THE HORSE ADMINISTRATION BUREAU. TOKYO 
June 13,1959

MYS 12839

35
959
25
314 


\section{CONTENTS}

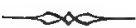

Page

I. Introduction . . . . . . . . . . . . . . . . 1

II. Short History of the Appearances and Spread of

Infectious Anemia among Horses . . . . . . . . 6

III. Pathogenesis . . . . . . . . . . . . . . . . . 10

IV. Modes of Infection . . . . . . . . . . . 18

V. Pathologic Anatomy and Histology . . . . . . . 29

VI. Symptomatology . . . . . . . . . . . . . 34

VII. Course and Prognosis . . . . . . . . . . 40

VIII. Diagnosis . . . . . . . . . . . . . . . 41

IX. Therapy . . . . . . . . . . . . . . . . . 42

X. Immunization. . . . . . . . . . . . . . . 44

XI. Preventive Inoculation and Disinfection. . . . . . 47

XII. Draft of Law for the Prevention of Infectious Anemia . 51 


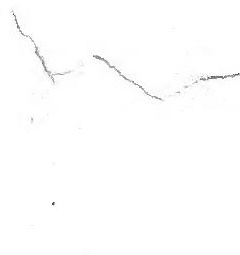




\section{REPORT ON THE RESULTS OBTAINED BY THE SPECIAL COMMITTEE FOR IN- VESTIGATION OF INFECTIOUS ANEMIA OF HORSE.}

\section{INTRODUCTION.}

a. Organization of the Committee for the Investigation of Infectious Anemia of Horse.

The Special Committee for the Investigation of Infectious Anemia of Horse was organized by the Government in July, 1909, and it has been put under the control of the Bureau of Horse Administration. The reason for establishing the committee is as follows:

Lately outbreaks of a peculiar horse disease were noticed at several important breeding districts in Hokkaidō and the north-eastern part of Hondō (main island of Japan). Several hundreds have already been lost both in the Remount Depôt of Military Horses and among horse owners. This disease, which causes pernicious anemia, is mainly confined to the pasturing districts. Since almost all the horses that contract the disease are sure to die, it has created considerable alarm among horse breeders in Japan. Despite the fact that its etiology had been assiduously investigated at several governmental institutions, satisfactory results had not been obtained. Moreover, in the affected regions no means of checking the disease had ever been attempted because of the entire lack of knowledge of its causative factors. Judging from the 
invasion and the progress of symptoms we cannot deny that the disease is of an infectious nature. Should its etiology and preventive means not be made clear soon, the disease would cause an unrestorable loss upon the horses of the whole empire of Japan.

To meet this immediate need the Special Committee for the Investigation of Infectious Anemia of Horse was organized. The Chief of the Bureau of Horse Administration was made ex officio chief of the Committee and other members of it were nominated from several institutions.

By the committee researches regarding the causative factors of this peculiar disease have been carried on, and at the same time the methods of prevention have been investigated so as to remove the fear of future outbreaks from horse breeders in Japan.

The names and titles of the members of the Committee first nominated at the time of organization are as follows:-

Chief of the committee:

Count Masakata Terauchi, General, Chief of the Bureau of Horse Administration.

Commissioners:

Sennosuke Katsushima, Jyuigakuhakushi, Professor of Agricultural College, Tokyo Imperial University.

Hatsukuma Tokishige, Jyuigakuhakushi, Expert

Department of Agriculture and Commerce.

Rokuro Imaizumi, Jyuigakuhakushi, Colonel A. V. C.

Kenkichi Tange, Inspeetor Bureau of Horse Administraiten.

Yuji Kishimoto, Inspector Bureau of Horse Administration (Secretary of the Committee.) 
Kiyoshi Shiga, Igakuhakushi, Expert Institute for Infectious Diseases.

Naoshi Nitta, Jyuigakuhakushi, Assistant Professor of Agricultural College, Tokyo Imperial University.

Tomiya Sasaki, Major A. V. C.

Since the organization of the Committee, there have been changes of the members, and at the time of submitting this report, March 1914, the Committee consists of the following members:-

Chief of the Committee:

Toshinobu. Asakawa, Major General, Chief Bureau of the Horse Administration.

Commissioners :

Sennosuke Katsushima, Jyuigakuhakushi, Professor of Agricultural College, Tokyo Imperial University.

Keitaro Tsuno, Jyuigakuhakushi, Professor of Agricultural College, Tokyo Imperial University.

Yuji Kishimoto, Expert Bureau of Horse Administration. (Secretary of the Committee).

Kiyoshi Shiga, Igakuhakushi, Expert Institute for Infectious Diseases.

Mikinosuke Miyajima, Igakuhakushi, Expert Institute for Infectious Diseases.

Kiichiro Muto, Jyuigakuhakushi, Colonel A. V. C. Tokutaro Uyeno, Cavalry Colonel.

Naoshi Nitta, Jyuigakuhakushi, Assistant Professor of Agricultural College, Tokyo Imperial University.

Iichiro Otsuka, Captain A. V. C.

Assistant Commissioners : 
Makoto Koidzumi, Assistant Expert Institute for Infectious Diseases.

Temporary Commissioners :

Heitaro Yoshida, Cavalry Colonel.

Ginzo Yanagisawa, Jyuigakuhakushi, Colonel A. V. C.

Toshinobu Miyamoto, Major A. V. C.

From the following gentlemen especial help was asked during the progress of investigations:

Iwakichi Kani, Iyuigakuhakushi, Professor of Morioka Higher Agricultural College.

Naoyoshi Kii, Captain A. V. C.

Kanta Nimi, Captain A. V. C.

\section{b. Object and Methods of Investigations.}

The object of the Committee is to investigate the nature of the disease and to find out the most practical methods of treatment and prevention for immediate need, leaving detailed scientific research on the disease for the future.

The investigations have been carried on along the following three lines, and the commissioners have been divided into three groups accordingly:

1. Careful investigations of the conditions of initial outbreak and spread of the disease, clinical examination and treatments, methods of prevention, etc.

2. Protistologic, pathologic and chemical study of the disease.

3. Comparison of the disease with similar ones occurring among the horses of foreign countries.

At the request of the commissioners the following experiment stations were founded at different times during the past six years: 


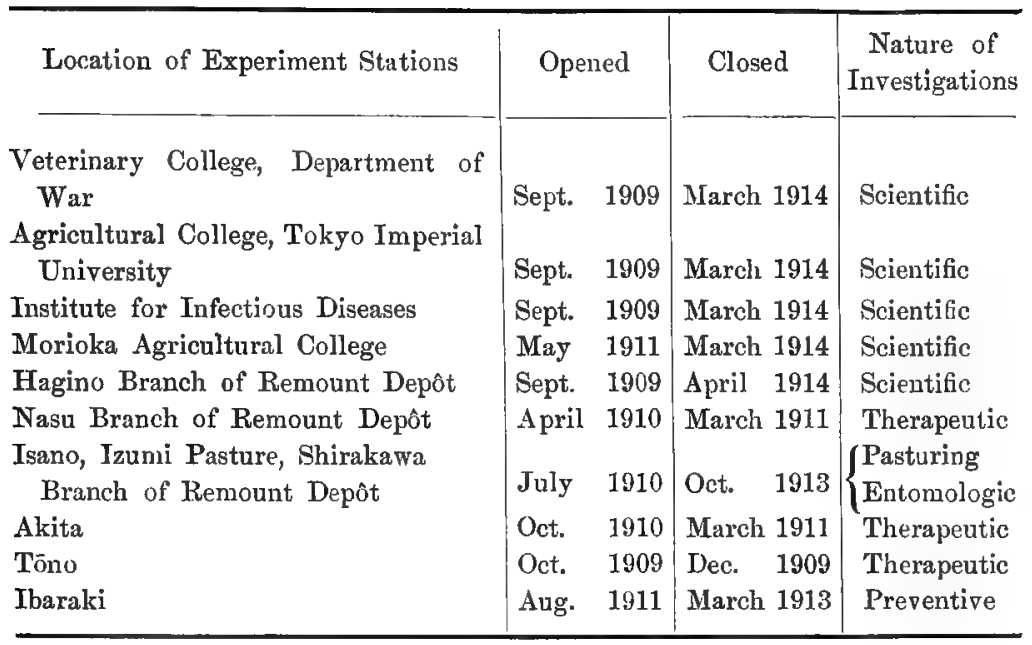

\section{c. Results of Investigations.}

As the chief results accomplished by the Committee the following five items may be mentioned:

I. In September 1909 "Rules for the Remedy of Infectious Anemia of Horse" and "Explanation of Symptoms" were drawn up by the Committee and submitted to the Government as a draft for the "Investigation for the Prevention of Infectious Anemia of Horse" to be issued by the latter.

II. In May 1911 a draft for the Laws for the Prevention of Infectious Anemia of Horse and various rules therewith connected were discussed by the Committee and resolutions were made.

III. In December 1911 the Results of Investigation obtained by the Special Committee for Infectious Anemia of Horse were discussed by the Committee and were made public. 
IV. In April 1913 a project of Law for the Prevention of Infectious Anemia and rules therewith connected were again discussed and amended (vide of the Preventive Methods on p. 51).

V. In September 1913 the Report upon the Results obtained by the Special Committee for Investigation of Infectious Anemia of Horse was discussed, revised and supplemented by the Committee.

The investigation of the Committee lasted for four years and ten months, extending from July 1909 to March 1914. Animals used for experiments by the Committee numbered over a thousand; 980 horses, 1 donkey, 7 calves, 5 goats, 6 sheep, 7 pigs and a few other small animals. The entire expenditure amounted to over 80,000 yen.

\section{SHORT HISTORY OF THE APPEARANCES AND SPREAD OF INFECTIOUS ANEMIA AMONG HORSES.}

It is certain that in olden times infectious anemia did not exist among Japanese horses, but we have at present no way of ascertaining when and how outbreak of the disease took place for the first time in this country. Usually the appearance of the disease becomes known to the public at the time when it has already been spreading for several years to a considerable area, outof-the-way pasturing districts among mountains being first invaded, where ignorant people totally lack the knowledge of preventive methods.

From as many traditions and other data as we could gather, we can say with a high degree of probability that the first authentic record of the out- 
break of the disease was in about the year 1895 in the province of Hidaka, Hokkaido and in Yokohama of Aomori Prefecture. However, we have no evidence to decide in which of these two districts the disease first appeared. The reason why the disease occurred in places so far separated from each other is not hard to find, since in former days horses were very often transported by Japanese boats between Hidaka, Yokohama and Noheji. In Hokkaidō the disease spread from Hidaka into the plains of Tokachi, Kushiro and Kitami. In Hondo, the main island of Japan, on the other hand, the invansion started in the west from the above centre, Yokohama, proceeded to Akita prefecture (mainly Yuri country), then to the boundary of Tsugaru and stopped in the neighboring county, Akumi of Yamagata Prefecture. To the east it entered the adjacent Ichinohe County, Iwate Prefecture, then Sannohe County at the boundary of Aomori Prefecture. Thence it affected horses of the pasturing districts of Iwate Prefecture. Local outbreaks were noticed in the pastures of Fukushima and Ibaraki Prefecture; these undoubtedly were due to the sale of convalescent horses. In the same way the disease came into the prefectures of Tochigi, Gumma, Saitama, Chiba and Yamanashi, and many patients were produced there. Since in these districts horses are not raised in pastures, no fresh cases have been recorded in the neighborhood.

It may be concluded that the disease is confined to a part of Hokkaido and several district of the northeastern part of Hondo, and does not invade the southern part of Japan, because the pasturing is restricted in the north, this being one of the necessary conditions for the transmission of the disease.

The exact number of yearly losses is also unknown 
for the same reason as mentioned above. But inferring from what has been learned from frequent visits of the commissioners to the infected regions, losses are not heavy at any place in the first year of outbreak. From the second year on the patients gradually increase in number. Tremendous losses follow for some years. A great majority of the horses succumb to the disease. Then slowly it is abated.

Any district once affected seems to retain the disease for a considerable number of years. An instance in the province of Hidaka will illustrate this. Five or six years after the initial outbreak in a small village, Horoizumi, Urakawa Branch of Hokkaidō-chō (the entire province of Hidaka is under the control of this office) they began to keep statistics of horses dying of the disease.

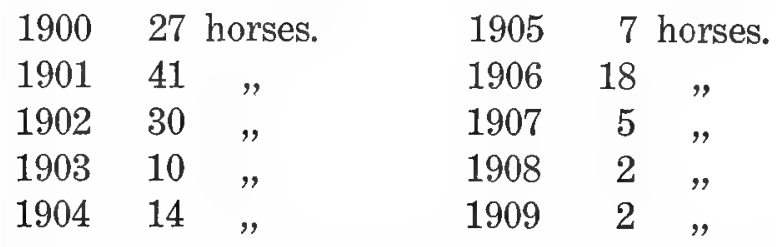

From this table it will be seen that even more than ten years after the initial outbreak cases are still found.

The following will show that if proper preventive methods be applied, the damage occasioned by the disease will be considerably reduced, even if it is not possible to check it out of the district at once. In July 1911 it was reported that many horses were affected by the disease in a part of Sekimoto village, Taga Country, Ibaraki Prefecture, and our careful investigation revealed that the virus was imported from a neighboring pasture of the prefecture of Fukushima, where a great many horses had already succumbed to it. We soon came to the conclusion that this was an excellent place to carry 
out most profitably the experiments of prevention. As the first step all the horses were carefully examined. Those which showed even the slightest sign of the symptoms characteristic of the disease were bought and killed. As the result of this 107 horses of the village were reduced to 45,24 having died of the disease and 38 having been killed. This method proved to be very effective, since not a single horse of those remaining succumbed to the disease, though some have had a weak form of it. This seems to give an important sidelight that, though one infected horse is able to affect the whole herd, yet those animals which have had a slight form of the disease seem to acquire immunity and do not show any further symptoms at all.

We regret that we do not have exact statistics of yearly losses in various localities. However, the following numbers show the totals of cases reported by Local Governors since the establishment of the Commitee:

\begin{tabular}{|c|c|}
\hline 1910 & 341 \\
\hline 1911 & 376 \\
\hline 1912 & 359 \\
\hline 1913 & 263 \\
\hline
\end{tabular}

It may be added that the above cases are those which were reported to the Local Governors by the horse owners and veterinary practitioners. Besides these, there must have been cases which remained unreported due either to the negligence on the part of horse owners or to the lack of regulations for reporting. In any event we can estimate without grave mistake the whole number of patients in Japan to be between 400 and 500. Lately the cases are decreasing in number due partly to the fact that the disease has already spread as extensively as it possibly can and partly to the immunity acquired by the horses of affected districts. 
The horses belonging to the Remount Depôt of Military Horses have contracted the disease and a considerable number has already been lost. When the initial outbreak took place we do not know, but since 1905 a great many horses have died from deaths attributed to the diseases of the spinal cord, of the heart, anemia, etc. in the pastures of the Branches of the Remount Depôrt at Hagino, Yamagata Prefecture, Kajiyazawa, Miyagi Prefecture, Rokuhara, Iwate Prefecture. In 1907 it was discovered that all the losses had been due to infectious pernicious anemia. Ever since that date the disease has invaded all the pastures of the Branches of the Remount Depôt and the maximum losses came in 1910, the number of the horses that died and were killed taken togereaches over 500. Since then the number of patients has decreased as the result of strictly carrying out the preventive measures. As the virus is usually introduced into the pastures of the Branches of the Remount Depôt through two-year horses, which look healthy, when bought, and afterward prove to have been infected when pastured in the summer, our constant effort to anihilate the disease completely has not as yet been rewarded. And even now fairly heavy losses take place every year.

\section{PATHOGENESIS.}

\section{A. Nature of the Disease.}

The great spread of infectious anemia in pastures is due to the transmission of the virus from one individual to another by insects. Very seldom are horses infected through the alimentary canal in stables.

Unless the disease is of a subacute nature and death 
soon ensues, it is usually characterized by its insiduous and chronic course. The first few months after infection frequent intermittent febrile attacks occur. But when the illness is alleviated a little, patients as a rule acquire the power of resistance against the virus, and fiebrile attacks decrease in number until they return to normal. It need hardly be mentioned that the virus is retained in the body for a considerable length of time.

The chief pathologic change of the disease consists in a marked decrease of the red blood corpuscles. Also more or less noticeable lesions are found in the heart, liver, spleen, kidneys, lymph-glands, bone-marrow, etc. Mortality is between $30 \%$ and $70 \%$, according to the conditions of the disease, climate, care of patients, etc.

Blood examinations of the affected horses reveal that three to four millions of red corpuscles are present in $1 \mathrm{c.m} . \mathrm{m}$., and in advanced cases less than one million in so much blood; that is, less than one-seventh of the number of red corpuscles in found normal blood (six to seven millions). If the red corpuscles of the patient's blood be precipitated to the bottom of a graduate, its coagulation being prevented, the corpuscular layer measures less than one-tenth the whole volume, while in normal blood it is more than four-tenths.

\section{B. Etiology.}

In order to detect the causative agent of the disease the blood and viscera of patients were subjected to all possible microscopical and culture methods with negative results. It was found that the virus passes through Berkefeld's and Chamberland's filter. It should be remarked that the apparatus had been tested with Bacillus prodigiosus beforehand and had been proved really 
bacteria-proof. From this we can infer that the disease is caused by one of the ultramicroscopic organisms.

That the virus is present in the blood and various viscera was demonstrated by the following experiments. An animal of quite advanced case was killed and ten different organs were taken out of its cadaver (blood, spleen, liver, kidneys, spinal cord, lymph-glands, salivary glands, muscles, lungs and bone-marrow) Each organ was injected into two healthy individuals, thus using twenty experimental horses altogether (Experimental horses-extra series Nos. 9-18, 21-30). Every one of them became affected in the course of from eleven to fifteen days. Urine and milk of a patient were separately injected into healthy individuals (Experimental horses-extra series Nos. 1-3). They also showed typical symptoms of the disease. The conclusion can be drawn from the above expriment that the virus is excreted in urine and milk. We could not, however, detect it in the faeces and sweat of sick horses.

If blood be drawn from a patient during a febrile attack and even a small quantity of it, say 5 c.c., be injected into a healthy horse, the latter thus becomes affected. A horse receiving intravenously 0.5 c.c. of serum diluted with saline solution showed characteristic symptoms of the disease after an incubation of 17 days.

According to the results obtained by the experiments performed upon 16 horses, the first febrile attack came from 9 to 29 days after a subcutaneous inoculation of 20 c.c. of the patient's blood. In one instance, in which a horse received 100 c.c. of the patient's blood subcutaneously, the latent period was only three days.

Healthy horses (Experimental horses Nos. 510-630) receiving patient's blood with $2.5 \%-5 \%$ of sodium taurocholate remained unaffected. This seems to indicate 
that the causative agent is not of bacterial but of protozoan nature.

\section{The Resistance of the Virus Against Various Physical and Chemical Conditions.}

I. Heat.-It was demonstrated that the virulent blood heated at a temperature of $60^{\circ} \mathrm{C}$. for an hour loses its virulence, as was tested by injecting it into healthy horses.

II. Sun-light.-Two Petri dishes, each containing 10 c.c. of the virulent serum, were exposed in the garden of the Institute for Infectious Diseases for two hours between noon and 2 P. M. of August 18 (the day was clear, not a single cloud; thermometer readings in the room $31^{\circ} \mathrm{C}$. and in the sun $49^{\circ} \mathrm{C}$.). The serum thus treated was afterward injected into healthy horses without any effect whatever.

III. Cold.-Virulent blood was put in a test-tube and exposed out of doors from December to April in the northern part of Japan (Yamagata Prefecture), during which time the temperature was often as low as $-8^{\circ}$ or $-9^{\circ}$ C., and it snowed several times. But that the virus had not lost its vitality, was shown by the fact that of four healthy animals (Experimental horses Nos. 48-51) receiving the blood thus treated all became affected.

The resistance of the virus against various disinfectants will be described later on.

\section{The Retention of the Virus for a Long Time in the Blood of Convalescent Horses.}

Not only can it be demonstrated that the virus of the disease is in the blood at intervals between febrile attacks, 
but it was also proved that it is retained in the blood for a long time even after recovery, and causes future outbreaks of the malady. In order to determine accurately the length of the time of retention of the virus in clinically recovered horses, we performed the following experiments.

Blood was drawn from

\begin{tabular}{|c|c|c|c|c|}
\hline 2 horses & 3 & ont & fte & overy. \\
\hline 2 & 6 & ", & ", & ", \\
\hline " & 8 & ", & ," & ", \\
\hline , & 9 & $"$ & $"$ & " \\
\hline 1 horse & 11 & , & $"$ & $"$ \\
\hline 4 horses & 12 & , & $"$ & $"$ \\
\hline$"$ & 13 & ", & , & $"$ \\
\hline $2 \quad$, & 14 & ", & " & " \\
\hline 1 horse & 16 & , & ", & $"$ \\
\hline , & 22 & ", & " & " \\
\hline
\end{tabular}

and was injected subcutaneously into 21 healthy horses. All became affected except two; one was of the number which received the serum taken three months after recovery and the other of those that received the serum taken thirteen months after recovery. Since the virus was not detected in the blood of these two experimental horses, they were killed and various viscera (liver, spleen, lungs, kidneys, lymph-glands, brain, muscles, bone-marow, salivary glands) were taken out of the cadavers. They were again injected into healthy animals. All of them manifested afterwards characteristic symptoms of the disease. This undoubtedly shows that the virus was present in the viscera though it was not demonstrated in the blood.

Three horses, which had completely recovered from heavy attack of the disease and has been subjected to 
ordinary work in a regiment, were selected for expriments. Their blood was drawn from time to time for three years and was injected into healthy animals. By the blood taken from a horse three years after recovery two out of three became affected within the usual period of incubation. In another experiment on two horses, which received the blood drawn four years after recovery, we found that one of them became ill after a latent period of 65 days. In still another experiment on two horses, which received the blood taken five years after recovery, the result was negative.

These experiments clearly show that the virus gradually diminishes its power and finally vanishes.

\section{Relation Between Patients and Their Offsprings.}

Though the infection of the disease in stable is extremely rare, the ralation between patients and their offsprings must be of a peculiar nature. One can readily notice in affected districts that young horses rarely contract the disease. The following experiments were undertaken to clear up this point.

1. Blood was drawn from four foals brought forth by affected mothers and was inoculated into four horses (Experimental horses Nos. 443, 445, 446, 464). One was affected, two showed doubtful symptoms and one gave negative result.

2. Milk of patients (30-100 c.c.) was injected into three horses (Experimental horses Nos. 563, 443 566). All became affected after latent periods of 24, 46 and 42 days, respectively.

3. Milk of patients was given every morning internally to healthy stallions and colts, but no positive result was obtained. 
4. Blood was drawn from a young horse of an affected mare, before it began sucking, and was injected intravenously into two healthy horses (Experimental horses Nos. 554 and 615). Two showed typical symptoms of the malady.

5. A foal from an affected mare was stopped sucking at the age of a little over four months and was kept outside the stable. It became ill and died with typical symptoms of infectious anemia.

From the above experiments we may be able to conclude that the virus is present in the milk of a patient and that the virus also penetrates into the fetus through the placenta. And the transmission of the disease to the young seems to be accomplished more frequently during its intrauterine life than through sucking viruscontaining milk.

\section{Experiments on Various Animals.}

In case the donkey contracts the disease, it ususally shows acute symptoms and dies rather suddenly. As to animals outside the equine family, the pig is most susceptible; young goats and sheep also show slight febrile conditions; calves, rats, guinea-pigs, rabbits and dogs have no susceptibility at all towards the disease.

\section{Pig.}

1. Young pig. -10 c.c. of the blood of a patient was injected subcutaneously into a young pig. After eleven days its bodily temperature suddenly rose as high as $40.2^{\circ} \mathrm{C}$, locomotion was markedly interfered with, appetite became poor, the heart action forcible, frequent shiverings, finally it fell into an unconscious state and died after two days (vide accompanying table). 
Experimental infectious anemia in a young pig (female) No. 2. at the Experiment Station of the Army Veterinary College.-1910

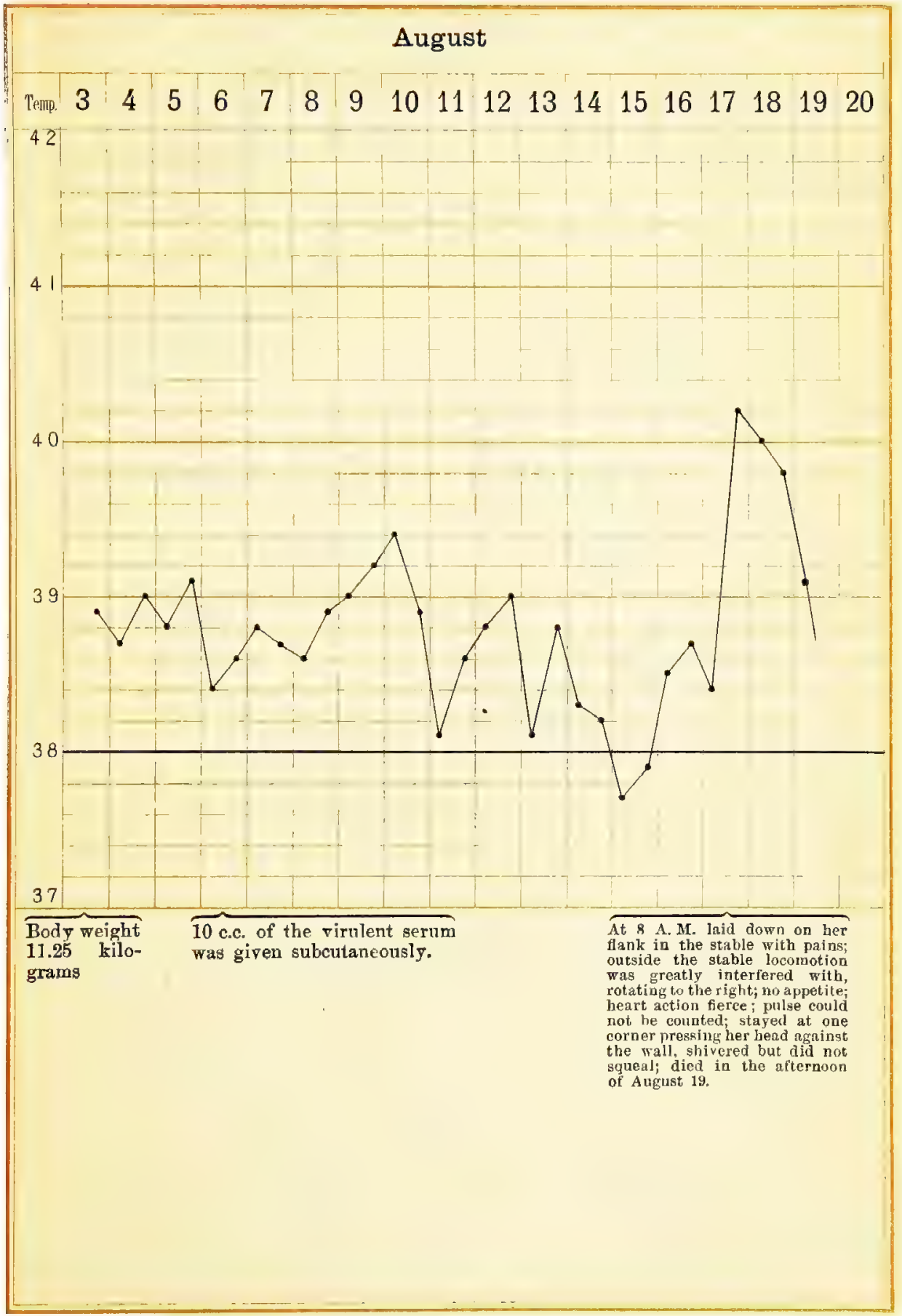


TABLE II.

Experimental iniectious anemia in a donkey: the Army Veterinary Coliege.- 1910

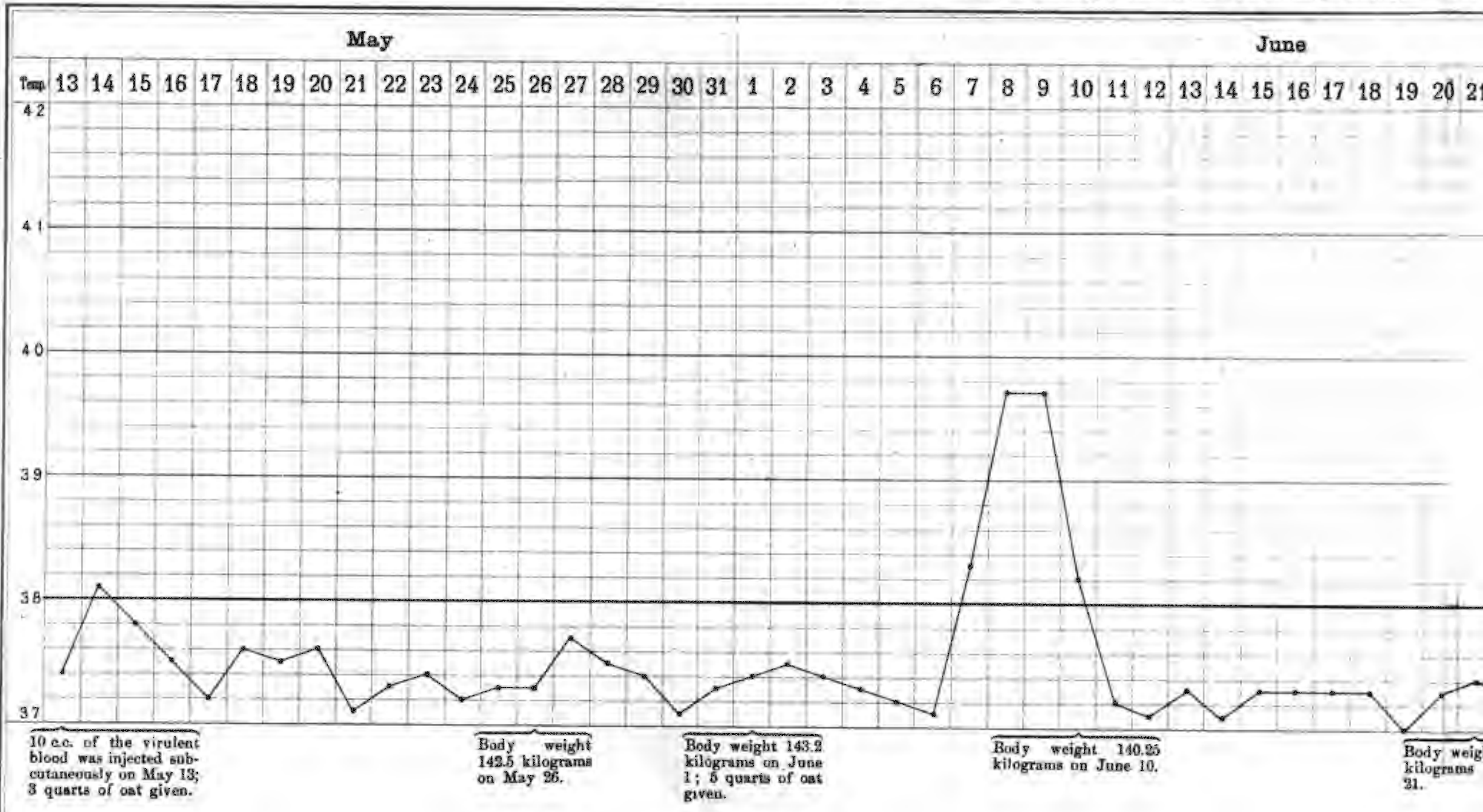


TABLE II.

Experimental infectious anemia in a donkey: the Army Veterinary College.-1910

June

July

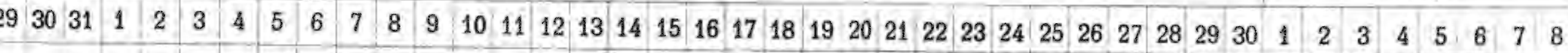

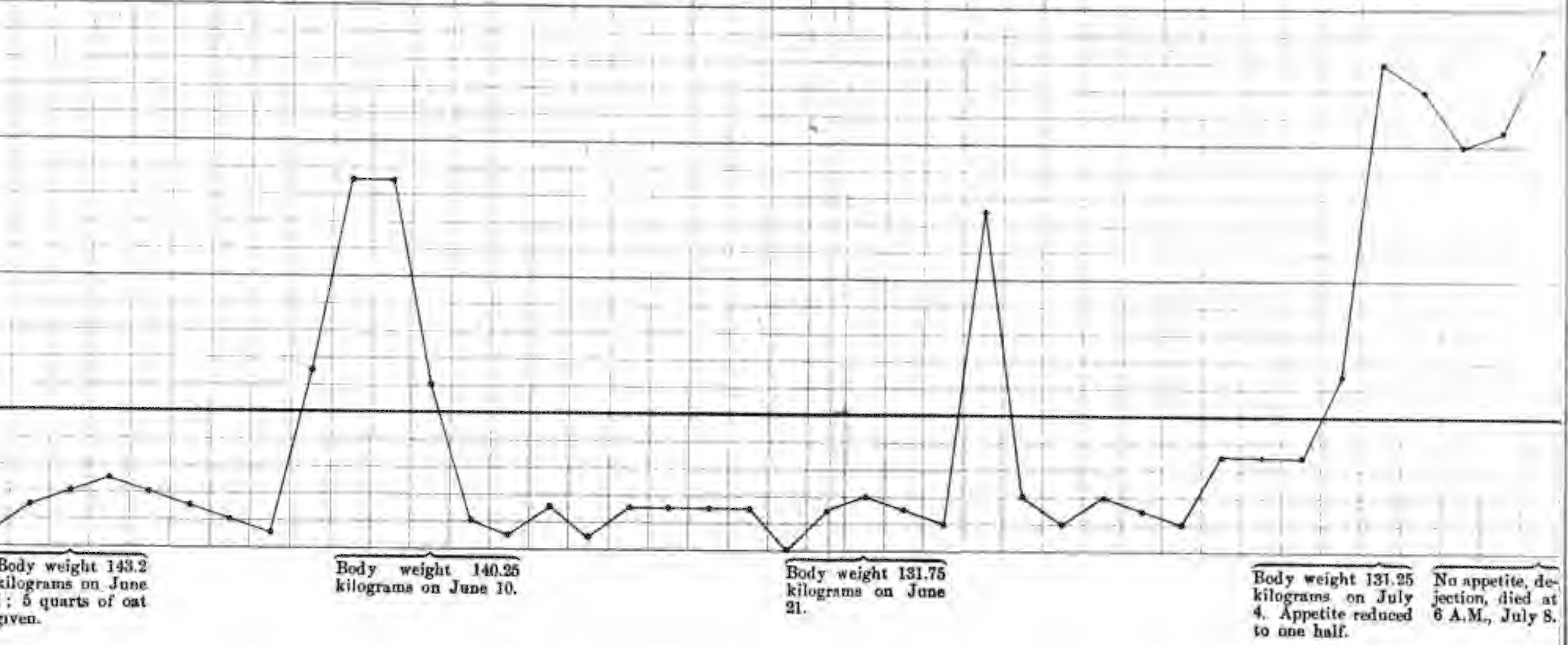
given kilograme on Jane

4. Rasns on July

to one half. 

2. Young pig. -10 c.c. of the virulent blood was injected into a young pig. It died suddenly from a febrile attack after five days.

3. Half-grown pig. -10 c.c. of the virulent blood was injected into a half-grown pig. It did not become affected. Consequently one month later 20 c.c. of the blood of the pig was injected into a healthy horse (Experimental horse No. 53). It became affected after a latent period of 27 days. From this experiment it may be concluded that not only is the virus retained for a month in the pig, but also that it increased in amount while in the pig.

\section{Donkey.}

10. c.c. of the virulent citrated plasma was given subcutaneously to a donkey. The first febrile attack came 24 days afterwards, thermometer reading being $39.7^{\circ} \mathrm{C}$ in the maximum. After four days the temperature became normal. The second attack came after 21 days, the temperature staying at $40^{\circ}-40.5^{\circ} \mathrm{C}$. for five days, when the patient died. It lost 11.25 kilograms during the malady (vide accompanying table).

\section{Goat.}

Young goat. -5.0 c.c. of a patient's blood was injected into a young goat. Temperature rose after three weeks. Febrile condition lasted for five days, the maximun temperature being $40.5^{\circ} \mathrm{C}$. After that the temperature returned to normal.

50 c.c. of the blood of an affected horse was injected into a goat. It did not show any sign of illness at all. 100 c.c. of the blood was drawn after 38 days from the goat and was injected into a healthy horse (Experi- 
mental horse No. 60). It had been watched for four months and a half without being affected.

Besides, experiments were performed upon several goats and sheep. The results were generally negative.

\section{Calf.}

$40-50$ c.c. of the virulent blood was injected into four calves. None of them showed any sign of the disease. Their sera and bile were used for preventive experiments with no effect whatever.

\section{MODES OF INFECTION.}

In investigating the appearance and spread of infectious anemia among horses in Japan, it has been learned that very few cases develop in the stable, while in the pasture it usually spreads with an astonishing rapidity, a great majority or even the entire herd succumbing to it. To take a concreie example. At the Branch Remount Depôt, where horses are pastured during the summer, many cases are met with, while in the regiments, where horses are quartered in stables, the disease does not spread out of them, though a few sporadic cases may occur among reserve horses. No cases have as yet been recorded, in which outbreak took place in the districts, where horses are usually kept in stables; the spread of the disease having been restricted to pasturing districts. What seem to be sporadic cases encountered in breeding or working districts are in reality those introduced from other parts of the country.

From what has been mentioned above, it can be conjectured that there must be conditions peculiar to 
the pasture, which favor infection of the disease. Consequently detailed investigations have been carried out along the following four lines, namely: 1. Infectivity of the patients' excretion; 2. Infection through the alimentary canal; 3 . Infection in the stable and; 4 . Infection in natural environment. Towards the solution of the above problems the Committee has devoted most of its energy and time extending over six whole years. The number of the horses used for these experiments reached about 150 .

\section{A. Infectivity of the Patients' Excretion.}

1. Urine.-Two horses received subcutaneously $\mathbf{1 0 0}$ c.c. of the patient's urine and one other horse 150 c.c. After latent periods of 11-17 days all three became affected. Three horses received subcutaneously 15 c.c. of a patient's urine. They showed typical symptoms after 15-25 days (Experimental horses-extra series Nos. 2, 3, 31).

2. Faeces.-Faeces of a patient were mixed with saline solution and were treated with Berkefeld's filter. The filtrate was injected into a horse without any effect whatever. Hence we may be able to conclude that the virus passes out in urine but not in faeces. This result agrees well with that obtained by feeding experiments to be described in the next section.

\section{B. Infection through the Alimentary Canal.}

100-200 c.c. of the patient's urine was given every day internally to two horses (Experimental horses-extra series Nos. 34. 47). All became affected in a little over thirty days. One horse (Experimental horse No. 479) re- 
ceiving 100 c.c. twice a day (once in the morning and the other time in the evening) for over 120 days was not infected at all.

100 c.c. of the patient's blood was given to four horses (Experimental horses-extra series Nos. 9. 10. 43. 44.) mixed with the feed every day or every other day. Two out of the four became ill after about 50 days, and the remaining escaped affection.

Faeces of a patient were given mixed with the feed every day to five horses. The result was negative.

From the above experiments conclusion can be reached that the entrance of the virus into a healthy individual through its alimentary canal can actually take place, but, since infection by this mode is accomplished only by protracted application of an unnatural method, contact infection in nature, if any, must be a very slow and limited process.

\section{Infection in the Stable.}

Patients and healthy individuals were quartered in the same stable to see if infection takes place among them. Of eleven horses used for the experiment only two became affected. The experiments were performed purposely during the winter, when the development of insects is suspended.

1. For six months, from August 1910 to January 1910, three healthy animals (Experimental horses Nos. 6-8) were kept with the patients at Hagino Branch Remount Depôt. One horse became affected after 64 days, and in the other two the result was ambiguous.

2. For five months, from December 1910 to April 1911, three healthy horses (Experimental horses Nos. 90, 108, 487) were kept with a patient at the Experiment 
Station of the Agricultural College, Tokyo Imperial University. One of them was infected, and the other two showed negative result.

3. For about ten months, from May 1911 to February 1912, two horses (Experimental horses Nos. 105, 115) were kept with a patient at the Institute for Infectious Diseases. Neither of them became ill.

From the above experiments we can reach the conclusion that infection very rarely occurs in the stable. This result agrees with that of another experiment carried on in a stable from which the access of insects was prevented by means of wire-netting (vide the next section).

\section{Infection in Natural Environment.}

Several experiments were performed in the open air to determine the actual course of transmission of the disease. The following are the main problems to be solved:

1. Does the virus winter in pasture?

2. How does infection take place when healthy animals are kept with patients or virus-carriers in the same pasture?

3. How is the virus transmitted from one horse to another in pasture?

4. How is the disease related with blood-sucking insects?

In order to solve the above questions pasturing experiments were carried on during four summers (19091913). Their progress and results therefrom are as follows :

1. It had long been known that terrible infection of the disease took place in pasture, but we did not have any information regarding the length of time of 
the retention of the virus there. To see whether or no the virus in our case persists for a long time, as in Texas fever, five healthy horses were kept over a month in the autumn of 1909 in the Higashima pasture belonging to Hagino Branch of the Remount Depôt of the Military Horses, where many patients had been produced year after year until 1908. The result was negative. But from this we cannot deny the presence of the virus in the field; this negative result may be due to the absence of the transmitter of the disease; for the experiment was performed rather late in the season. To exclude the above possibility the same experiment was repeated in 1910 at the Masugata section of Izumi pasture belonging to the Shirakawa Branch Remount Depôt, where patients had been exceptionally abundant in 1909. Should the virus, winter in some form or other, any healthy horses in the section would certainly become affected. Six horses good in flesh and spirits were pastured for 101 day in the summer (from July 5 to October 31), the usual season of prevalence of the disease. All subjects kept up their health in spite of the fact that during the experiment insects were thriving and the horses were not well nourished owing to weak growth of grass there.

These experiments clearly show that the virus of the disease is not retained for a long time in pasture as is the germ of anthrax. Any pasture can, therefore, be considered perfectly healthy, if the patients were produced in the preceding years.

2. It is a well known fact that infection of the disease usually takes place in the pasture, but not in the stable. However, to determine how dangerous the patients or the virus-carriers are in the case of the mixed pasturing, we must have recourse to pasturing 
experiments. They were, therefore, performed twice, once in 1910 and again in 1912, at Izumi prasture. In 1910 from July 5 to October 31 (119 days) four healthy horses (Experimental horses Nos. 61, 62, 63, 64) were allowed to live with the seven virus-carriers in a special section entirely separated from other herds. All of the subjects contracted the disease. Two years later a similar experiment was tried. For six months, from May 1 to October 31, 1912, four healthy horses (Experimental horses Nos. 471, 486, 492, 493,) were kept with two patients and two virus-carriers. All the horses became affected; the earliest case appeared in 16 days. In comparing the result of these experiments with that of the foregoing (pasturing of healthy horses alone) the difference is very pronounced, and we can hardly escape from the conclusion that the terrible spread of the disease was due to the intermingling of healthy horses with the patients or virus-carriers in the pasture.

3. How is the virus transmitted from the patients or virus-carriers to healthy animals? The virus is excreted in urine, it is true, but in order to induce the disease artificially a large quantity of the urine (repetition of the internal administration of more than 100 c.c. each time) must be given. Moreover, a large portion of the patients' urine would soon find its way into the ground after excreted, and what is left on the surface would be disinfected by the direct sun light. Urine, therefore, can safely be excluded from the causative factors of the transmission of the disease in the pasture.

To consider the difference between the pasture and the stable, excretion products are more abundant in the latter than in the former. But the proportion of cases appearing is just the reverse, as was described 
before. The cause of the infection must, therefore, be sought in a different direction. The ploblem of the transmission of the virus by the blood-sucking insects naturally suggests itself. In foreign countries experiments have been tried to test the theory of insect transmission in the allied diseases (infectious anemia of Europe, swamp fever in America), but no positive results have as yet been obtained. As a matter of fact some investigators disbelieve in such a theory. At present the relationships between the disease and insects, therefore, are obscure. To clear up the question, we performed on a large scale entomological experiments at a section of Izumi pasture, where insects abound. A wire-netting stable and wooden enclosures were constructed (vide figures appended at the end of the report). The wire-netting stable is a gigantic cage, so to speak, $16,3 \mathrm{~m}$. long, $7.2 \mathrm{~m}$. wide, on one side (north side) of which is a wooden wall, three other sides and the roof being made of fine wire-netting to prevent the access of the insects to the horses within. The wooden enclosure is a rectangular fenced area without a roof, $18.1 \mathrm{~m}$. long, and $10.9 \mathrm{~m}$. wide. Two or three enclosures were constructed with an interval of about $12.7 \mathrm{~m}$. between them. These were to separate herds. In the above wirenetting stable both healthy horses and the patients were kept together and were watched to see how the infection takes place without interference of insects.

Experiment I. - In 1911 one patient and four healthy horses (Experimental horses Nos. 397, 395, 399, 340) were let in. Two (Experimental horses Nos. 395, 397) become affected after a protracted latent period. The other two remained healthy.

Experiment II. - In 1912 six very advanced cases and two healthy horses (Experimental horses Nos. 475, 472) 
were kept together for four months. One (Experimental horse No. 475) became ill after six months, and the other remained perfectly healthy.

From these experiments it may be concluded that the disease can be propagated among the horses simply by living together without the aid of insects, provided the place be highly infested. But this mode of infection is very weak and cannot be compared with what takes place in mixed pasturing in the open air.

The next experiment consists in keeping the patients and the healthy horses in separate enclosures during the season of the development of insects. Thus intercourse between the two sorts of animals was cut off, free access of insects to the animals being allowed.

Experiment I.-In 1911, from July 5 to October 13, nine patients were kept in one enclosure to make it highly infested, while in one of the neighboring, healthy enclosures, four healthy animals (Experimental horses Nos. 341, 342, 404, 405) were received. The latter showed signs of being affected in one month and finally every one of them manifested symptoms of advanced stage of the disease.

Experiment II.-In 1912 five patients were put in to an enclosure; two of them died in a short time; one fell into a heavy form of the disease; two did not show marked symptoms though strongly emaciated. In the enclosure A two healthy horses (Experimental horses Nos. 466, 483) were kept throughout the whole length of the pasturing season. In the enclosure B four healthy horses two at a time, were put in. Three of them (Experimental horses Nos. 477, 491, 559) manifested typical symptoms; one (Experimental horse No. 560) remained unaffected. The reason why in the Experiment II. the proportion of the infection was smaller than in the 
Experiment I. may be sought in the fact that in the former the virus was rather rare in the patients' enclosure.

Experiment III.-In 1913 the above experiment was repeated extending from May 1 to October 31. Nine patients were received in one enclosure. Two healthy horses (Experimental horses Nos. 552, 564) were kept in the enclosure A during the experiment and in the enclosure B four horses (Experimental horses Nos. 572, 573 $565,634)$ were let in, two at a time. The process of the infection was carefully watched. The result was very striking, all the healthy animals contracting the disease.

The above three experiments clearly demonstrate that the disease can be transmitted without intercourse between the healthy and sick horses, when free access of insects is not prevented, and that under such circumstances the infection goes on in a degree as fierce as in the mixed pasturing. From this, the conclusion may be drawn that the transmission of the disease under consideration is accomplished only through the agency of insects that are capable of flying.

4. The insects and their allies, which occur in pastures and attack animals, are as follows: ticks, bot-flies, sand-flies, mosquitoes, horse-flies etc.

A. Ticks (Ixodidae)-Ticks have no power of flying and moreover if these parasites on the patients be transferred to the healthy horses, the latter do not become sick at all.

B. Bot-flies (Gastrophilus equi) - These do not belong to the blood-sucking insects, but since its larvae are found in the horse's stomach, the virus may thus be taken from the sick horses and transmitted to the healthy. To exclude the possibility several larvae were 
taken out of the stomach of a horse dying of this disease, crushed in a mortar, filtered, and injected into healthy animals, but the result was negative. Furthermore, in 1912 bot-flies were exterminated from all the horses before pasturing and it was noticed that the removal of the insect did not influence upon the spread of the disease in that particular summer.

C. Mosquitoes (Culecidae)-They can safely be excluded from our present problem; for they are found only in the stable and not in the pasture.

D. Sand-flies (Simulium)-This insect is very abundant in the pasture. The power of sucking blood is very strong; horses are, therefore, greatly annoyed by the sand-fly. This insect appears very early and stays until late autumn. Therefore there is a time when this insect monopolises the pasture, all other insects disappearing. Choosing such a time of the year healthy horses and the patients were kept near each other in the same pasture, preventing, however, the intermingling of these two groups of animals. None of the healthy horses contracted the disease. In spite of the fact that the sand-flies attacked both the healthy and the sick animals for nearly a month, the disease was not transmitted. Hence we have reached the conclusion that the sand-flies have nothing to do with the process of infection.

E. Stable-flies (Stomoxis calcitrans) - This is also a blood-sucking insect occurring as abundant and living as long as the sand-flies. It abounds in the stables of the plains. We, therefore, tried an experiment as early as 1908, letting the fly, which had sucked much blood from a patient, bite healthy horses; but the result was negative. During the season of the stable-fly, the patients and the healthy horses were kept in two enclosures near each other. The result here was also negative. 
Next, many flies were kept in the wire-netting stable with the healthy and affected horses and allowed to bite the animals freely. Excepting a case of doubtful infection (Experimental horse No. 472) among the healthy horses, the transmission of the disease was not so marked as in the mixed pasturing and in wooden enclosures. Hence the stable-flies cannot be taken as the true transmitter of the disease.

F. Horse-flies (Tabanidae)-These are most abundant in the pastures and attack horses violently. In the stables they are scarce. It must especially be mentioned that the spread of the disease coincides in time with the appearance of this insect. Therefore at the outset of the experiments we caught many horse-flies and tried to let them bite healthy horses, but we soon discovered it extremely difficult to keep them alive for any length of time. Moreover, we could not force them to suck blood out of the patients, though all the possible artificial means were tried. Not having been able to overcome these difficulties, we could not, to our regret, domonstrate experimentally that the horse-fly is an actual transmitter of the diesease. But deducing from the fact that the infection takes place both in the mixed pasturing and in the wood enclosures at the period of the appearance of horse-flies and that other blood-sucking insects are not likely to be the virus-transmitters, as was already described, we canot escape from the conclusion that the infection of the disease is accomplished through the agency of the horse-fly.

Several species of the horse-fly occur in the pasture, where the foregoing experiments were performed. The time of appearance differs in different species.

Chrysopus japonicus, WiEd. The first part of Maythe first part of June. 
Haematopota tristis, BIGoT. Latter part of Maythe first part of July, again in the first part of September.

Several species of Tabanus (T. chrysurus LoEw, $T$. trigonus CoQ., T. trigeminus CoQ., T. luridus FALL., T. rufidens Big., etc.) July, almost simultaneously, very abundant in Aug., disappear in October.

Inferring from the fact that in the pasturing experiments already mentioned the disease spreads both in May and June, when Chrysopus japonicus and Haematopota tristis appear, and in July and August, when several species of Tabanus develop, we can hardly avoid the conclusion that those horse-flies are the real transmitters of the infectious anemia among horses in Japan (vide Plates III. and IV.)

\section{PATHOLOGIC ANATOMY AND histologY.}

\section{A. Anatomical Changes.}

The acute and chronic cases of infectious anemia among horses differ somewhat from each other in the degree but not in the nature of their anatomical changes. The usual changes are general anemia, hydraemia, ecchymoses both in the mucosa and serosa, pericardial hydrops, inflammatory changes of the parenchyma, etc., and in general the disease shows symptoms which are characteristic of septicaemia. Observations on the changes of various viscera and tissues of the patients will now be described.

Carcasses are usually emaciated and anemic. They are, however, not so in the acute cases. Exposed mucous 
membrane is pale or whitish, often with petechiae and oedema. Rigor mortis is not complete in most cases. In the subcutaneous and intermuscular connective tissues ecchymoses, haemorrhages, gelatinous or bloody infiltrations are usually met with. In the blood vessels there is either a small quantity of thin blood or nothing at all. The muscles are as a rule soft, discolored and cloudy. In the chronic cases no especial changes take place in the muscles, excepting their general atrophy. The paniculus adiposus is rather thick, compared to a high emaciation of the cadaver.

The abdominal fluid increases in almost all cases. The peritoneum and mesentery have often ecchymoses of various sizes and shapes.

The stomach and intestine are always found full of contents. No especial changes are seen in the alimentary canal, excepting its catarrhic changes in a few cases.

In the acute cases or after several febrile attacks the spleen is ususally enlarged and sometimes becomes twice or three times as large as the normal size. Its capsule is distended, showing petechiae. The pulp becomes dark red giving an appearance of soft mud, and reminding one of that of anthrax. In the chronic cases the pulp increases both in volume and in hardness. Its section surface is grayish with a tint of reddish brown. But in the cases of slow progress such changes as splenic tumor are not seen.

The liver is in most cases enlarged accompanied by such changes as hyperaemia, haemosiderin infiltration, icterus, cloudy swelling, or fatty degeneration. Those which died of, or were killed after, several attacks of the disease, had the livers not only enlarged, but they were also provided on their surface with small white spots, powdery, net-like or cloud-like. These are situated 
between the two adjacent lobules and especially at the bottom of the indentation between two of the lobules. Sometimes they entirely circumscribe the lobule. The fleck is not a depression as in interstitial hepatitis. Neither is it an elevation as in fat infiltration. Sometimes the boundaries of the flecks become obscure spreading over the liver (especially on its indented surfaces) as large gray markings. Upon touching such a liver one finds that it is rather hard and compact (vide histologic changes).

In the acute cases the kidney is enlarged, softened, turbid and covered with small petechiae. It is richer in blood than any of the other organs, and consequently appears juicy and readily putrefies. Even in the chronic cases petechiae are sometimes found in the cortex. In the papillae haematoidin infarct is sometimes seen. In many cases the mucous membrane of the urinary bladder has ecchymoses both new and old.

In the pleural cavity a small quantity of fluid is present. On the pleural membrane and on the diaphragm many petechiae of various sizes ranging from that of millet, or linseed to a pea are always met with. The lungs do not show any changes peculiar to the disease, but sometimes hyperaemia, haemorrhage, oedema and rarely bronchopneumonia are found.

In the pericardium a large quantity of transparant yellowish exudate is present (200-1500 c.c., usually $400-$ 500 c.c.). In the adipose tissue are usually found numerous thickly set petechiae, though this change is not so marked in the chronic cases.

The heart is relaxed dilated and with little contents. The heart muscles are soft and turbid. In the endo- and epicardium ecchymoses are invariably found and in the extreme cases they appear as though they were injected 
with blood. Occasionally gelatinous infilration is seen in the valves, but this change is not pronounced in the chronic cases.

The most prominent change of the disease is noticeably in the blood. It decreases immensely and in the extreme cases the lethal quantity of the blood drawn does not reach 10 litres. As to the detailed description of the changes in blood, the reader will find it in the next section.

The lymph-glands both superficial and visceral are more or less swollen, the largest reaching the size of a walnut or a hen's egg. This is especially the case with those of the mesentery and of the spleen. The glands are soft, juicy and pulpy in section surface. They are usually light reddish brown with yellow markings or grayish black flecks.

Changes of the bone-marrow is very marked next to those of blood. In the acute cases, the cross section of long bones, such as the femur, or humerus, shows that the bone-marrow changes wholly or in part into dark red with petechiae. In the chronic cases the change is not so extensive as in the acute form, but it develops as the foci. In the protracted cases a small number of foci are invariably present.

The central nervous system shows scarcely any change at all, excepting the increase of the fluid in the cavity of the arachnoid membrane and the lateral ventricles. Very rarely ecchymoses in the pia mater and small haemorrhagic foci in the gray matter of the spinal cord are found.

No macroscopic changes are met with in other organs, such as the pancreas, salivary glands, suprarenal body, thyroid gland, or walls of blood vessels. 


\section{B. Histologic Changes.}

The histologic changes of various tissues and organs correspond to the anatomical findings, e.g., anemia, extravasation, hypertrophy and degeneration of parenchymatous organs and the presence of haemoglobin crystals (seen also in fresh material) due to haemolysis. Especially noteworthy is the infiltration of small round cells in parenchymatous organs.

The lymph-glands and bone-marrow are always more or less swollen. The dark red part of the bone-marrow is rich in blood and poor in adipose cells, generally infiltrated by round cells. Often many eosinophile loucocytes and megalocytes are found in it. Sometimes haemorrhage takes place in the capillaries.

In the spleen are found haemorrhage, acute splenic tumor, haemoglobin crystals. Often one sees proliferation of the large mononuclear cells and marked increase of haemosiderin granules. In the chronic cases its matrix is always more or less enlarged.

In the liver one often meets with cloudy swelling, fat infiltration, atrophy of the liver cells, dilatation of capillaries, and infiltration of blood-pigment (especially haemosiderin). Marked is the infiltration of round cells in the interstitial substance and in the lobules. Fat infiltration does not take place in the margin of the lobules as is usually the case, but in the liver cells near the central vein (vide the colored plate at the end of the report).

In the kidneys are sometimes found haemorrhage, infiltration of round cells, cloudy swelling, and slight fat infiltration. In one instance the suprarenal body totally lacked chromatic substance. 
The heart muscle fibres are always cloudy and in some cases various stages of fatty degeneration have already set in.

In the mucosa of the stomach and intestine haemorrhage and slight cell inflltration are sometimes seen.

Very seldom small haemorrhagic spots are present in the central nervous system.

In conclusion we may mention that the main histologic changes of the disease consist in the disintegration of the red blood corpuscles resulting in haemosiderosis. It is not certain whether these chages in the circulatory system and general nutrition,-e.g. haemorrhages and fatty infiltration of various tissues and organs, -is due to anemia or direct action of the virus. In any event the disease resembles leucaemia in various symptoms, viz. the presence of elements like round cells in the liver, kindneys, mucosa of the alimentary canal, etc., and the proliferation of the pulp-cells in the spleen. These pathologic changes seem to be of the same nature as the hypertrophy of the bone-marrow and the lymph-glands.

\section{SYMPTOMATOLOGY.}

General Symptoms. - The prominent features of the disease are irregular recurrences of fevers and progressive anemia. At first the febrile attack comes suddenly and it subsides almost completely in a short time. This being repeated for several times the patient usually falls into anemia and emaciation. During the progress of the disease, such symptoms as paleness of visible mucous membrane, oedema at various parts of the body, septicaemic phases and exhaustion appear. Of these, the 
most marked feature of the disease is the disorder of the function of the heart.

General Conditions. - At the first stage of the disease, the appetite of the animal is as good as usual, but the patient shows a dull and fatigued appearance. The movement of the limbs is somewhat interfered with. The patient usually slightly responds to whipping and sometimes does not react to the digital pressure at the loin. It is liable to be greatly fatigued with light exercises. As the illness progresses, the patient becomes dull and likes to stand still at a dark place such as a corner of a stable, lowering its head. The power of attention is so weakened, that the patient does not seem to have any inclination to get rid of flies, even if they swarm about it. With each febrile attack its emaciation and weakness gradually increase and finally the patient falls to the typical case of pernicious anemia. As the fatal termination approaches, the animal staggers, and lies down on its side; for its hind quarters do not have strength enough to keep it standing.

Bodily temperature. - At the outset of the malady, the temperature suddenly rises to $39^{\circ}-40^{\circ} \mathrm{C}$. and after remaining so for a day or two (in some cases for many days), it falls to normal very rapidly. Frequency of the febrible attacks is variable. Of 274 cases, 116 had attacks 2-9 times a month; in 93, it came after a month; and in 30 , after two months. After three months, the frequency of recurrence decreases, as is shown in the following six cases. The attack occurred once in 1 case, twice in 3 cases, and three times in 2 cases after more than six months. In one or two cases it came once after seven months. In chronic cases, the animal keeps up for some time a subfebrile condition of $38^{\circ}-39^{\circ} \mathrm{C}$.; sometimes such a case changes into an acute form with 
a sudden elevation of temperature higher than $39^{\circ} \mathrm{C}$., or febrile attacks recur periodically for more than a year. Near the final termination, the animal usually shows a collapse temperature lower than $36^{\circ} \mathrm{C}$.

Visible mucous membrane.-The eye-lids and conjunctiva are, at the outset, of a dirty yellowish red or yellowish brown color, slightly swollen, humid, showing a ramiform injection of the blood vessels. After some time the mucous membrane is gradually discolored and becomes yellowish gray or pale or even whitish in the extreme cases; the swelling disappears. The tinge of other mucous membrane alters somewhat similar to that of the conjunctiva.

Petechiae.-During the febrile attacks petechiae appear in the conjunctiva, the mucous membrane of the nose, gingiva and other parts, and the mucosa of the rectum, etc. Usually they range from the size of a pinhead to a millet grain. Often, however, they aggregate themselves to form a haemorrhagic area as large as a finger-ball.

Oedema. - Oedema usually appears at the belly, prepuce, lower portions of the limbs, face massetor region, lips, head, thorax, etc. Its extension varies proportionally with the condition of the malady. As in the case of petechial fever, the facial, laryngeal and tracheal regions are so much swollen, that respiration and deglutition are interfered with. In rare cases oedema suddenly vanishes immediately prior to death.

Superficial lymph-gland.-Especially in acute cases the superficial lymph-glands are more or less swollen. Those of the submaxillary space, perinaeum, knee folds, etc. become prominent. But they neither harden nor suppurate.

Circulatory system.-During the febrile attacks the 
frequency of the pulse ranges between 50 and 90 per minute and in many cases it keeps a medium strength. Towards the fatal termination, the pulse becomes weak and may reach 120 or more. Finally it becomes imperceptible. In the patient of emaciating stage, the pulse is usually irregular, unequal and sometimes intermittent. It should be noted that the pulse of the patient is greatly accelerated by its locomotion even to a very short distance. The heart-beat becomes forcible and it can often be seem from without on the left side of the chest. On auscultation, the cardial sounds are usually loud. The first sound is always prolonged, muffled or divided, so that in some cases one can hear two distinct sounds. Similar disturbances sometimes may be heard in the second sound or in the both syrchronously. In other cases a noise is heard simultaneously with or immediately after the first. In still other cases, a pause comes between the first and the second. Pulsation of the jugular veins is a symptom characteristic of the disease. In severe cases, it extends above the middle part of the neck.

Respiratory system. - The alteration of the tinge of the nasal musous membrane has already been alluded to. A very small quantity of mucus may be shed but no rhinorrhoea takes place. Towards the final issue, the animal sheds foam when oedema pulmonum occurs. Upon percussion or auscultation, nothing abnormal is found in the lungs. Number of the respirations is normal, but in the case of a high fever it is 50-60 per minute. By exertion the rate of respiration of the patient is increased more than in the healthy horses.

Digestive tract:-During the febrile attacks the patient's appetite is, more or less impaired, as is usually the case with other febrile diseases or is sometimes 
totally lacking. But no change is found in the digestive tract. Not infrequently a patient in an advanced case continues eating even when it can no longer stand on its feet.

The peristaltic action of the intestine is usually normal, but sometimes it is a little accelerated. The faeces are normal, but near the fatal termination they are softened or sometimes coated with a slimy mucus. By the time this stage is reached the anus is relaxed in many cases and temperature reading is thus rendered impossible.

Spleen.-The swelling of the spleen is a constant phenomenon during the febrile attacks, as can be detected by rectal examination. In chronic cases or interfebrile periods, the swelling varies in degree. In the cases of extreme anemia, the spleen is swollen very little or not at all.

Urogenital system. - The oedema of the scrotum and prepuce and the petechiae of the vaginal mucous membrane are usually found. Increased frequency of micturition and also increase of urine in quantity are constant symptoms. The urine is light yellow or brownish yellow, thin and turbid. Its reaction is alkaline in most cases. Its specific gravity is normal (1.028-1.045). Albumin is always present during febrile attacks, the maximum being 10.5\%. During interfebrile periods and in chronic cases, no albumin is found. The solid constituent usually decreases.

General character of blood.-The patient's blood is thin, and poor in coagulatings power. The plasma and corpuscles are quickly separated. The separation of serum is not so good as normal. This is especially the case with the chronic or severe form of the illness, in which coagulation does not take place after several days' 
standing. The color of the serum is light yellow instead of orange of the normal. But in the incipient stage this distinction is not marked.

Haemoglobin. - At the outset of the disease one finds very little alteration in the haemoglobin of the blood, i.e., 60\%-70\% estimating with Gower's haemoglobinometer, instead of $70 \%-85 \%$ as is found in the blood of the healthy horses. As the disease advances the haemoglobin gradually decreases to $25 \%-15 \%$.

Shape and kinds of the red blood corpuscles.-In the biginning of the disease one can find hardly any alteration in the red blood corpuscles. As the disease advances, they gradually lose their power of resistance. A number of microcytes, and a small number of macrocytes and poikilocytes are found. Haematoblasts have not as yet been demonstrated. Few morphological changes occur in red blood corpuscles, the notable thing being their enormous decrease in number.

Number of red blood corpuscles - At the incipient stage the number of red blood corpuscles is almost the same as in the normal blood. But in the patient in anemic phase, which is characteristic of the disease, the number decreases with striking rapidity. It is not infrequent in extreme cases that the number of red blood corpuscles are reduced to one-seventh of the average physiological number $(1,120,000$ in 1 c.mm.).

Number of leucocytes.-Leucocytes also decrease in absolute number but not so much as the red blood corpuscles do. The ratio of red blood. corpuscles to leucocytes, therefore, is always greater than prevails in normal blood. It is not infrequent that the number of leucocytes reach over 10,000 in 1 c.mm.

Kinds of leucocytes. - Usually a comparatively large number of neutral polynuclear, transitional and eosino- 
phile cells are found in addition to the lymph-cells of various sizes. Besides these a small number of the mastcells and a great many large mononuclear cells are present.

Blood-platelets and haemokonia. - During febrile attacks, one notices a considerable increase of blood platelets. Their shape and modes of aggregation are very variable. Besides these, minute spherical or elliptical granules are present. They are identical with the haemokonia found in horses suffering from other febrile diseases.

\section{COURSE AND PROGNOSIS.}

The disease can conveniently be divided into the acute, the subacute, and the chronic, but no sharp line of demarkation can be drawn between them. In the acute form, high temperature remains for some time. After from a few days to two weeks from the beginning of the disease, the final termination comes always by the appearance of symptoms of septicaemia.

Those animals, which pass through the first febrile attack, may become better for a time, but a very small proportion of the patients completely recover. In many cases, another febrile exacerbation returns after two or three weeks being accompanied by worse symptoms than the first. They then change into acute cases and sometimes may remain for nearly a month. In chronic cases, the disease continues from a few months to over a year, during which time the condition of the disease fluctutates with the recurrence of febrile attacks, or it changes into an acute type, and the final issue comes from anemia and emaciation.

Prognosis of the disease is generally doubtful, and 
all the horses that contract the worst type of the disease are sure to die with the frequent recurrence of febrile attacks. Horses, which have apparently recovered, are liable to become ill again by certain unsanitary conditions, especially by unfavorable climate or hard labor. Such patients usually die of another attack after a few months or in the following year. But in case the course of the disease is good, the patient acquires immunity and febrile fits come no longer. Not only do such patients look healthy (despite the fact that they are still the virus-carriers) but they can stand any ordinary labor.

\section{DIAGNOSIS.}

During febrile exacerbation, one can easily diagnose the disease from the symptoms already mentioned. But both in chronic cases with normal temperature and during interfebrile periods, differential diagnosis is extremely difficult, or almost impossible. One has to infer simply from such symptoms as emaciation, alterations of the mucous membrane and a peculiar change in. the cardial sounds. In such cases the only sure method of diagnosis is to inoculate the blood of a suspected patient to a healthy horse and to watch the development of typical symptoms in the horse inoculated.

Diagnosis by serum reaction:-

1. Complement fixation test.

a) Experiments using the patient's serum as antigen and the immune serum as antibody.

b) Experiments using aqueous or alcoholic extracts of the patient's bone-marrow, liver, spleen and suprarenal body as antigen and the immune serum as antibody. 
2. Cuorin reaction.

Experiments on precipitation reaction against the patient's serum by means of Teruuchi's E.R. lecithin.

3. Experiments on haemolysis using extracts of the patient's organs.

4. Experiments on precipitation reaction using extracts of the patient's organs against the immune serum.

It should especially be noticed that all the above tests were tried, without yielding anything towards the establishment of the diagnosis; for their results were about the same as those of the control performed with the serum and organs of normal horses. In short, all our efforts towards the discovery of a method of diagnosing at the very beginning of the disease turned out to be a failure.

\section{THERAPY.}

In the first place, we made a series of experiments with a number of medicines that might possibly destroy the virus. However, none of them being found to be of any promise, we were obliged to be content, for the time being, with the hope of increasing the resistance of the patient against the disease. We experimented with all the available forms of therapeutics taking the specific nature of the disease into consideration, that is, infectionsness, severe anemia, recurrence of high fever and the slow and prolonged course of the disease itself. The results were all unsatisfactory. However the following may be mentioned for future reference.

a) Peru-balsam.-10 gr. of Peru-balsam per day was continuously administered for more than a month with 
a marked improvement; the multiplication of red blood corpuscles and the increase of the body weight were observed. But it could neither stop the recurrence of the febrile attacks nor destroy the virus.

b) Quinine chloride and quinine tannate. $-5 \mathrm{gr}$. of the former and $10 \mathrm{gr}$. of the latter were given each day for a week or two with a promising effect for some time, but the continuance of the administration in severe cases might result in collapse.

Sodium salicylate (25.0 gr. per day), thiokol (10.0 gr. per day), ichthyol (10.0 gr. per day), sodium iodide (5.0 gr. per day), merkurol (0.5 gr. per day), quinine chloride (5.0 gr. per day) and other quinine salts.-Each of these medicines was given to each five of sick horses, while eight control cases were kept, which were left without treatment. The medicines were given every other week for 12 weeks. The results were found to be quite unsatisfactory, for a uniform improvement without exacerbation both in the experimental and control cases were observed. Though the effect of these medicines was not clearly shown in the experiments, quinine cloride was found to have some good effects upon the condition of the patient and the increase of the body weight.

c) Collargol.-The intravenous injection of $0.15 \mathrm{gr}$. of collargol will make the temperature rise for a while, but it will fall to normal in less than 24 hours. The transitory disappearance of the oedema and petechiae is noticed. It does not, however, stop the recurrence of febrile attacks. Moreover, if the administration is continued for several days at a time, the marked weakness of the heart and worse symptoms will set in.

d) Arsenic preparations. - Prof. Ehrlich kindly supplied us with arsenophenylglycin (8.0-12.0 gr., i.e., 0.02-0.03 per $1 \mathrm{klgr}$. of the body weighwat $\mathrm{s}$ injected intravenously) 
and salvarsan (intravenous injection of $4.0 \mathrm{gr}$. twice). They brought about no better effects. Atoxyl, ferrum kakodylate, sodium kakodylate, potassium arsenate were tried in vain.

e) So also were veratrine, thymol, wood tar, antimonium sulphate, lecithin, cholesterine, nuclein acid, antifebrine, phenacetine, glyceline extract of the bonemarrow and sodium bicarbonate. These were given either subcutaneously or per os.

Care of the patient and allopathy.

1. Excercise, labor and exposure, e.g., to extreme heat and cold, winds, snow and rain are apt to bring about exacerbation. The guard against these untoward conditions results in the abatement of febrile attacks and improves the course of the disease.

2. Cardiaca, tonics, and digestives are effective to abate the symptoms.

3. Nutritious and easily digestible food improves the condition of the patient and consequently tend to increase the resistance of the constitution.

\section{IMMUNIZATION.}

It has been observed that the animal that survived the disease no longer contracts it even if a large quantity of the virulent blood is inoculated. Thus a certain degree of immunity seems unquestionably to be acquired, but whether or no the serum of these immunized horses possesses any therapeutic or preventive properties must be decided by a systematic study. Accordingly, seven recovered horses were selected, in which increasing inoculations were made with the following results:- 
We injected 2 c.c. of the serum of an affected horse, which was gradually increased up to $2000-4000$ c.c. with a pause of 3 to 6 days. Only three of the seven horses were made perfectly immune, while two died of infectious anemia during the course of the treatment, and with the remaining two it was necessary to stop the treatment, because of the swellings and hyperaesthesia at the site of inoculation. The protocol of one of the perfectly immunized horses is given here.

Immunized horse (extra series No. 1.) Aug. 7 (1909) virulent serum A..... 2.0 c.c.

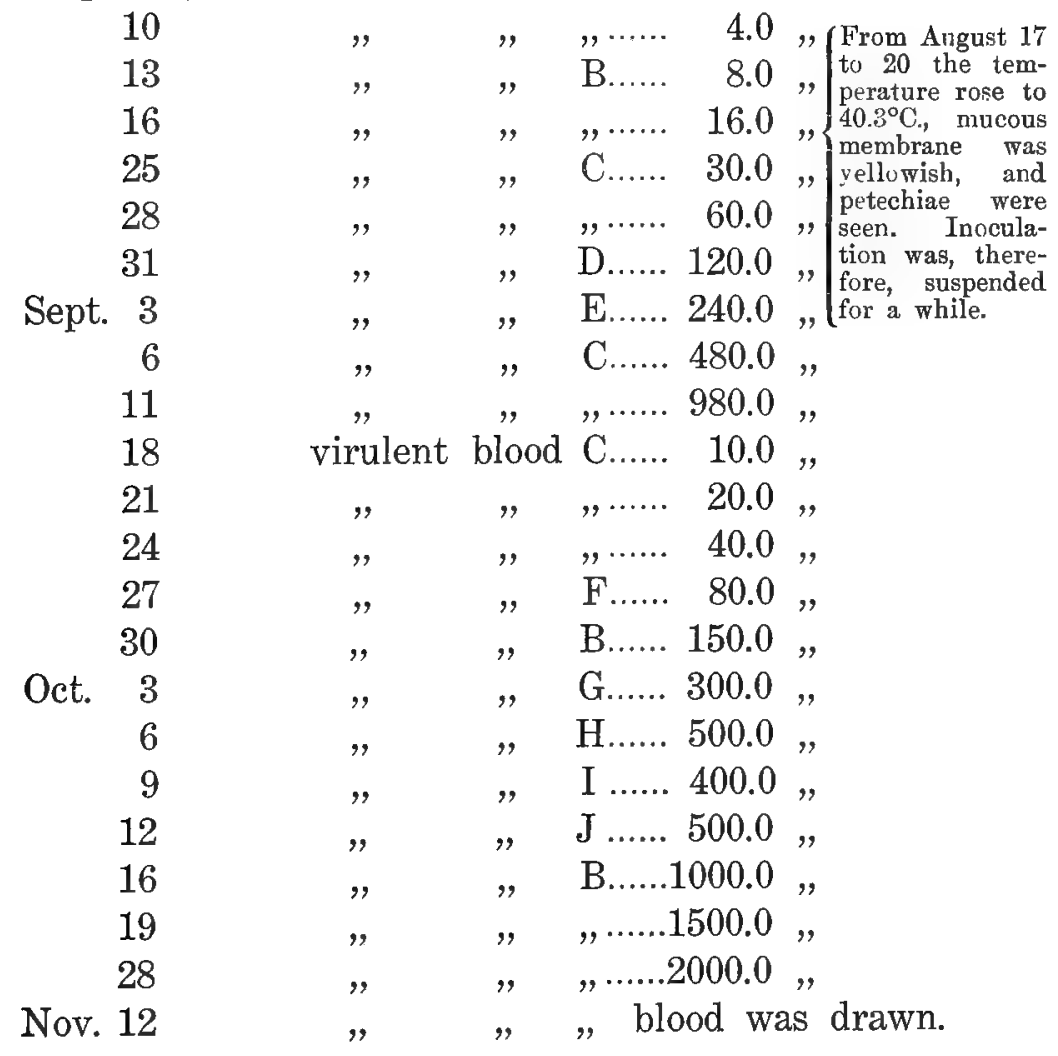


In order to ascertain the presence of the immune body, the immunized and the virulent sera were mixed and injected hypodermically to healthy horses. The results are given in the following table.

\begin{tabular}{|c|c|c|c|}
\hline $\begin{array}{l}\text { Experimental } \\
\text { Horse }\end{array}$ & $\begin{array}{l}\text { Immune } \\
\text { serum }\end{array}$ & $\begin{array}{l}\text { Virulent } \\
\text { serum }\end{array}$ & Results \\
\hline No. 8 & 100.0 c.c. & 10.0 c.c. & $\begin{array}{l}\text { Symptoms appear- } \\
\text { ed in } 13 \text { days }\end{array}$ \\
\hline No. 9 & 100.0 & 10.0, & $\begin{array}{l}\text { Symptoms appear- } \\
\text { ed in } 13 \text { days }\end{array}$ \\
\hline No. $10^{*}$ & 20.0 & $5.0 "$ & $\begin{array}{l}\text { No symptoms over } \\
3 \text { months }\end{array}$ \\
\hline No. 11 & 20.0 & 5.0, & $\begin{array}{l}\text { Symptoms appear- } \\
\text { ed in } 22 \text { days }\end{array}$ \\
\hline
\end{tabular}

From the above experiment, it is concluded that the immune serum contained no preventive property against the artificial infection. Besides, a new supposition was entertained that the virus might be contained in the blood of an immunized horse, for we had an evidence of the presence of the germ in the blood of an animal for a long time after an apparent recovery from the disease was noticed. The following experiment was performed in order to test the validity of our supposition.

Experimental Horse Immune serum

No. 13
20.0 c.c.
Results

Symptoms appeared in 15 days

From the above experiment, it becames clear that immune serum does contain the virus, and that it can

* The horse No. 10 must have had natural immunity; for it did not become ill even when it was inoculated with the virulent serum alone after a certain pause. 
not be used for therapeutic purposes; for it has no influence upon the virus. Moreover, the actual application in many cases has shown that it has no beneficial effect upon the temperature and other general symptoms.

It should especially be mentioned here that isolysin is found in the immune serum, if the blood corpuscles have not been excluded from the material used as antigen; for the patient that had been treated with such serum suffered from a severe case of anemia on the day following inoculation. A similar effect was produced upon a healthy horse, in which the erythrocyte-count fell suddenly from $8,000,000$ to $2,700,000$ on the day following injection.

\section{PREVENTIVE INOCULATION AND DISINFECTION.}

From what has already been described, it is certain that the horse may be made immune against infectious anemia, and we made a number of experiments to effect the preventive inoculation. The results of all these experiments, however, turned out to be negative. They will be briefly described in this report not because of their having had any practical value, but because they contain some interesting facts concerning the nature of the disease.

\section{A. Experimental Preventive Inoculation with the Sterilized Virus.}

The virulent serum that had been sterilized at $60^{\circ} \mathrm{C}$. for one hour was inoculated into healthy horses. After 
a certain pause, some of them were again inoculated with the virus and they all became ill.

\section{B. Experimental Preventive Inoculation with the Attenuated and the Modified Virus.}

1. A goat was inoculated continuously for months with the virulent serum. Its blood was drawn on the 10th-15th day from the last inoculation and the serum was prepared. The serum was then inoculated into healthy horses to see if it had any preventive efficacy upon the disease.

Experimental goat No. 1. received the virulent serum subcutaneously for four days (from August 28, 1910) and again for six days (from September 4, 1910), the quantity of the last inoculation being 100.0 c.c. The blood was drawn on the eleventh day from the last inoculation.

Experimental goat No. 2. received four subcutaneous inoculations with the virulent serum in the course of the period extending from August 28 to November 11, the last dose being 50.0 c.c. The blood was drawn on the 13th day.

Experimental goat No. 3 received three subcutaneous inoculations of the virulent blood, the last dose being 40.0 c.c. The blood was drawn on the 13 th day.

Experimental horse No. 95 received intravenous inoculation of 50.0 c.c. of the blood of Experimental goat No. 1. No change took place for 33 days. It was then inoculated with 20.0 c.c. of the virulent serum, and at last, it contracted the disease with a period of incubation of 11 days. 
Experimental horse No. 449 received intravenous inoculation of 50.0 c.c. of the serum of Experimental goats No. 2 and 3. No change was noticed for 76 days. 40.0 c.c. of the serum of Experimental goat No. 3 was then inoculated intravenously. Nothing happened for 55 days. It then received an intravenous inoculation of 20.0 c.c. of the virulent serum. It contracted the disease with a period of incubation of 9 days.

The results of the above experiments alone will not be strong enough to decide whether the virus disappears or simply loses its virulence by passing the goat. Should the latter supposition be correct, we might be able to prevent natural infection by the administration of the goat's serum. To test this, Experimental horses (Nos. 500,516 and 553) received the goat's serum before they were pastured with the patients. All the experimental horses became ill.

2. A pig received the virulent serum and its blood was drawn on the third day and again after one month. Each time it was inoculated into healthy horses (Nos. 53 and 85), which became ill will a period of incubation of 30-40 days. Thus it was ascertained that the virus could not be attenuated by passing through the pig, and that the material that had been obtained from the pig, therefore, could not be used in prophylactic inoculation.

3. A calf that had been inoculated with the virulent blood was killed. Its serum and bile were then inoculated into heathly horses with negative results. One instance of this experiment is as follows:-

On August 22, 1911, 50 c.c. of the virulent serum was inoculated into a calf. After 26 days it was killed and its blood and bile were drawn.

Experimental horse No. 112 received 40.0 c.c. of, 
the calf's serum subcutaneously. After 14 days, it again received 20.0 c.c. of the virulent serum under the skin. With a period of incubation of 12 days it became ill.

Experimental horse No. 452 received 40.0 c.c. of the calf's serum under the skin. After 40 days it was inoculated with 50.0 c.c. of the virulent serum. Symptoms of the disease appeared on the 17th day.

Experimental horse No. 398 received 30.0 c.c. of the calf's bile at two places. The sites of inoculation became swollen and suppurated. It received 20.0 c.c. of the virulent blood after 14 days, and it became ill with a period of incubation of 18 days.

Experimental horse No. 445 received 20.0 c.c. of the calf's bile at two places. Swellings were noticed at the sites of inoculation, but they were soon absorbed without suppuration. After 60 days the horse received 50.0 c.c. of the virulent serum. With an incubation period of 21 days it contracted the disease.

\section{Experimental Preventive Inoculation with the Immune Serum.}

The immune serum was made sterile either by adding $0.5 \%$ of tricresol solution or by heating at $60^{\circ} \mathrm{C}$. for one hour, and its prophylactic efficacy was tested in the following manner. 50.0 c.c. of the serum was inoculated into horses once a month through the entire period in which they were kept in the same pasture with the patients. The horse (No. 468) that was treated with tricresol serum became ill after 96 days. One of the two horses (No. 488) that received the heated serum contracted the disease after 152 days, while the other (No. 480) remained healthy. 


\section{Disinfection.}

1. Carbolic acid. - In order to determine their efficacy in killing the virus, several disinfectants were experimented with by adding a certain quantity of each to the virulent serum, which was then injected into normal horses. Since we found out that constant results could never be obtained, for the reason that the quantity of the virus in the serum might vary with each case, we used in our experiment, a large quantity of the serum to reduce this variation. $4 \%$ carbolic acid solution was mixed in equal parts with $40-50$ c.c. of the serum, so that the efficacy of the mixture might be equal to the $2 \%$ solution of the disinfectant. The results showed that the $2 \%$ carbolic acid solution did not kill the virus in 15 minutes. In 30 minutes only an incomplete action sets in. In one hour it destroyed all the virus; for no symptoms were produced in the inoculated horse.

2. Chloroform and toluol.-These disinfectants were added in various quantities to the virulent serum and thoroughly shaken up. After 20 hours' standing the mixture was inoculated into experimental horses, which were all affected with typical symptoms. From this the conclusion may be drawn, that chloroform and toluol do not destroy the virus of infectious anemia.

\section{DRAFT OF LAW FOR THE PREVENTION OF INFECTIOUS ANEMIA.}

The Committee wished to apply to the prevention of infectious anemia among horses part of the Laws for the Prevention of Infectious Diseases of Domestic 
Animals, and to this end met three times, May 1911, January and April 1912. After discussions resolutions were made regarding the following draft.

\section{IMPERIAL ORDINANCE.}

The Regulation concerning glanders and farcy, that are provided in the Ordinances for the Prevention of the Infectious Diseases of Domestic Animals shall be applied to the case of infectious anemia among horses.

Supplementary rule.

This ordinance shall be put in force on and after (date).

\section{DEPARTMENTAL ORDINANCES.}

\section{Draft of Regulations for the Prevention of Infectious Anemia among Horses.}

Art. 1. The pasturing district, that is brought under the control of the Regulations for the Prevention of Infectious Anemia shall be called "prevention district."

Art. 2. Local Governors shall determine the prevention districts, and give notice thereof throughout the districts under their respective jurisdictions, and shall report thereon to the Minister of Agriculture and Commerce and inform the local governors of the neighbouring prefectures thereof.

Art. 3. Police officers, mayors, town headmen and village headmen shall report cases of infectious anemia to the local governors, when they receive reports from the owners of the diseased animals. 
Note:-In the city of Tokyo, Kyoto, Osaka and Nagoya the urban district headmen shall perform the duty imposed upon the town headmen or village headmen. This will be the same throughont the Regulations.

Art. 4. Horse-owners or those who have the charge of horses shall immediately report the death and slaughter of horses affected with infectious anemia to police officers, mayors, town headmen or villageheadmen.

Police officers, mayors, town headmen or village headmen, who receive such report shall report to the local governor.

Art. 5. The police officers, mayors, town headmen or village headmen in the same prevention districts shall inform with one another the fact that they have received such reports according to Arts. 3 and 4.

Art. 6. When there are indications of the spread of infectious anemia among horses in any prefecture, the local governor shall give notice of the provisions under Arts. 3 and 4 throughout the district under his jurisdiction and at the same time give a report thereof to both the Minister of Agriculture and Commerce and to the local governors of the neighbouring prefectures.

Art. 7. Local Governor shall station inspectors at several places in the prevention district and make them carry out physical examinations on all the horses.

They shall appoint these inspectors from officers belonging to them, city-, town-, and village- officials and veterinarians.

Art. 8. Physical examinations shall be carried on at least once a week during the epizootic season and once a month during the rest of the year.

Local Governors may increase or decrease the number of inspectors according to the condition of the outbreak. 
Art. 9. Police officers, mayors, town headmen and village headmen who have received reports or found out by inquiry a case of infectious anemia, shall immediately inform the inspectors thereof, who shall make examination at the place of occurrence.

Art. 10. In case inspectors find out patients or suspicious cases, they shall make the horse owners or those who have charge of the horses isolate the patients or kill them if necessary.

Art. 11. If the affected horses that were isolated according to Art. 10 recover, the excercise test shall carefully be performed with them. If perfectly normal, they may be set free.

Art. 12. In case there are indications of the epizootic within the prevention district, the local governor may prohibit the removal of horses in a certain region, or the introduction of affected horses or suspicious cases.

Local Governors shall give notification throughout the district under their jurisdiction, report to the Minister of Agriculture and Commerce and inform local governors of the neighbouring prefectures about the district set apart according to Art. 12.

Art. 13. Local Governors shall investigate the conditions of the outbreak of infectious anemia and shall report the results once a month to the Minister of Agriculture and Commerce according to the accompanying form (the form is omitted.)

Art. 14. Local Governors shall notify the people throughout the district under their jurisdiction, report to the Minister of Agriculture and Commerce and inform local governors of the neighbouring prefectures of the discontinuance of the enforcement of Arts. 2 and 12.

Supplementary rule :

This regulation shall be put in force on and after (date). 


\section{INSTRUCTIONS.}

In the enforcement of the Regulations for the Prevention of Infectious Anemia among Horses the following shall be observed.

Art. 1. When a case of infectious anemia occurs in a horse pasture, where horse-flies prevail, or on the common hay meadow, which is frequented by horses, these places shall be designated as "prevention districts" according to Art. 1. of the Regulations,"

Art. 2. The number of inspectors shall be made large enough to carry out the inspection of all the horses in the prevention district within a certain period of time, which is to be designated according to the severity of the epizootic.

Art. 3. All the cases that have been diagnosed to be positive by the inspectors are preferably to be killed.

Art. 4. Inspectors shall be appointed from the veterinarians, who have had experience in the treatment of cases of infectious anemia or who have taken the course in the study of this disease.

Art. 5. The prohibition of the removal of horses, that is provided in Art. 12 of the Regulations, shall be enforced in the following cases:-

a. In case the indications of the epizootic reaches so far as renders it neccesary to have the pasturing suspended.

b. In case the infection is supposed to have affected the whole herd, and for this reason communication of horses shall be stopped.

* By Regulations the Regulations for the Prevention of Infections Anenia among Horses is meant throughout the following articles. 
c. In case there is danger of the infection spreading to the horses of a healthy pasture by the free intercourse between the pastures.

\section{NOTIFICATIONS.}

\section{Rules for the Prevention of Infectious}

\section{Anemia among Horses.}

1. In case suspicious symptoms of the disease such as febrile attacks, emaciation or avertion to move should appear, without any apparent cause, the owner or those who have charge of the horses, shall have the patient examined by a veterinarian, and quickly report the fact in person or by letter to the nearest police station, police box, city hall, town office, or village office.

2. Both positive and suspicious cases of the disease shall be removed from the pasture and kept in the stable isolated from healthy ones.

3. The isolation stable of the preceeding article shall be so constructed as to cut off the direct sun light and to prevent the swarming of horse-flies.

4. If a positive case occurs among the pastured herd during the horse-fly season, the whole herd shall be considered to have been infected and brought under careful observation during the whole pasturing season.

5. In the preceeding case if the horse-owners or those who have charge of the horses wish to remove their horses from one pasture to another or to bring new horses into the herd, they must ask the advice of police officers, veterinarians or inspectors before so doing.

6. Horses suspected of infection shall be pastured separately from healthy horses during the following year. 
7. In case any healthy horses are made to work in the field where the disease prevails, they shall not be worked in the direct sun light in order to avoid the swarming horse flies.

8. The stable in which a case of the disease has appeared shall be made clean. The floor must be washed either with hot alkali or hot water. The earth under the floor must be removed by digging more than six inches deep and the hollow place shall be filled with clean soil. The floor straw, droppings and the earth containing dung and urine, that have been kept in heaps for two months, may be used as manure.

9. When diagnosis is established, the patient is preferably to be killed by the advice of the police officers, veterinarians, or inspectors.

10. The exercise test mentioned in the Regulations Art. 11 is to be performed according to the following indications :- At the outset the subject is made to walk with slow pace for 20-30 miuutes. The time of exercise is gradually to be increased up to 2 hours or more at the end of 2 weeks. The exercise must be done just hard enough to keep the subject perspiring all over the body.

11. The nature and symptoms of this disease will be briefly described in the following :-

Nature of the disease. - The disease is of an infectious nature, the virus being mainly transmitted from horse to horse by means of horse-flies. It spreads in the pasturing districts, and infection rarely takes place in the stable or when the horses are employed for work. It takes a slow course. The period of incubation varies in a great range; through experiments it was found to be from 1 to 9 weeks. In a severe case, the course of the disease is acute and death takes place 
within ten days. In lighter cases or when horses have more or less acquired immunity, the final issue may follow a sudden febrile attack which occurs on the 40th50 th day, or in several months or even several years. In some it was observed that the animal was able to perform ordinary work without any dangerous symptoms.

The virus may live for several years after the patient has apparently recovered and nothing abnormal is observed.

Excepting in acute cases, the patient will improve by care in the stable, rest from work, nutritious rations etc. and will eventually recover. Those recovered horses have some degree of resistance, so that even if a large quantity of the virulent blood is inoculated into them they will not show any symptoms of the disease, although they carry the virus for a long time.

Etiology. - The disease is caused by an ultramicroscopic organism, which passes through the clayfilter. It is as yet impossible to cultivate the virus artificially.

It is transmitted mainly by horse-flies (Tabanidae) in the field. The infection can be induced experimentalily per os.

Symptoms. - The disease begins with a febrile attack. The main symptoms are abnormality in palpitation, pulse, and visible mucous membrane. In light cases, the temperature does not rise above $39^{\circ} \mathrm{C}$., but in severe form, it reaches over $41^{\circ} \mathrm{C}$. In many cases the temperature falls to normal in a short time. One or two weeks or several weeks after, another exacerbation comes. Then comes another and so on. With each recurrence of the febrile attacks, the animal gradually falls into an anemic condition. But in some cases, the patient shows symptoms of anemia from the incipient stage. In the 
pasture, the patient stays separated from the rest of the herd, and does not respond to whipping. In the stable, the affected animal stands in one place lowering its head. If it is forced to move, it shows signs of fatigue and tendancy to perspire. Its locomotion is greatly interfered with. It does not react to pressing applied at its hind quarters. It lacks the power of lifting its tail. It is not inclined to get rid of flies, if they swarm about its body.

The pulse increases to 50-80-ca 100 per minute. Palpitation becomes forcible and can readily be felt on the chest. The heart action can even be seen from without. Pulsation of the jugular vein can also be noticed.

The heart sound is often muffled or intermittent or doubled.

Oedema is also a frequent symptom. It appears in the lower part of the head and neck, chest, belly, distal end of the extremities and external genital organ. In the incipient stage, the visible mucous membranes flushes, but, when anemia sets in, they gradually become yellowish white or grayish. Often dot-like small petechiae are seen.

The blood becomes thin and watery. The red blood corpuscles decrease extremely in number. If the blood is left to stand in a test-tube the corpuscular layer at the bottom does not reach half the thickness of that of normal blood.

Excepting during the febrile periods, the appetite is not impaired. The faeces do not show anything abnormal. The patient is liable to emaciation.

In acute cases, hypertrophied spleen can be felt upon rectal examination, while during the interfebrile periods and towards the last stage of anemia the spleen does not show enlargement at all. 
Temperature and Pulse Curves of a Typical Case of Infectious Anemia, Experimental Horse No. 332, Age 13 Years.

(at the Izumi Experiment Station). -1913

\section{August}

September

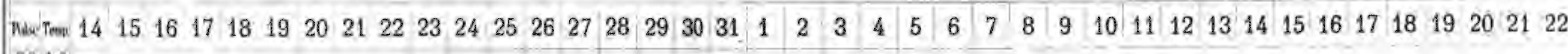
8042

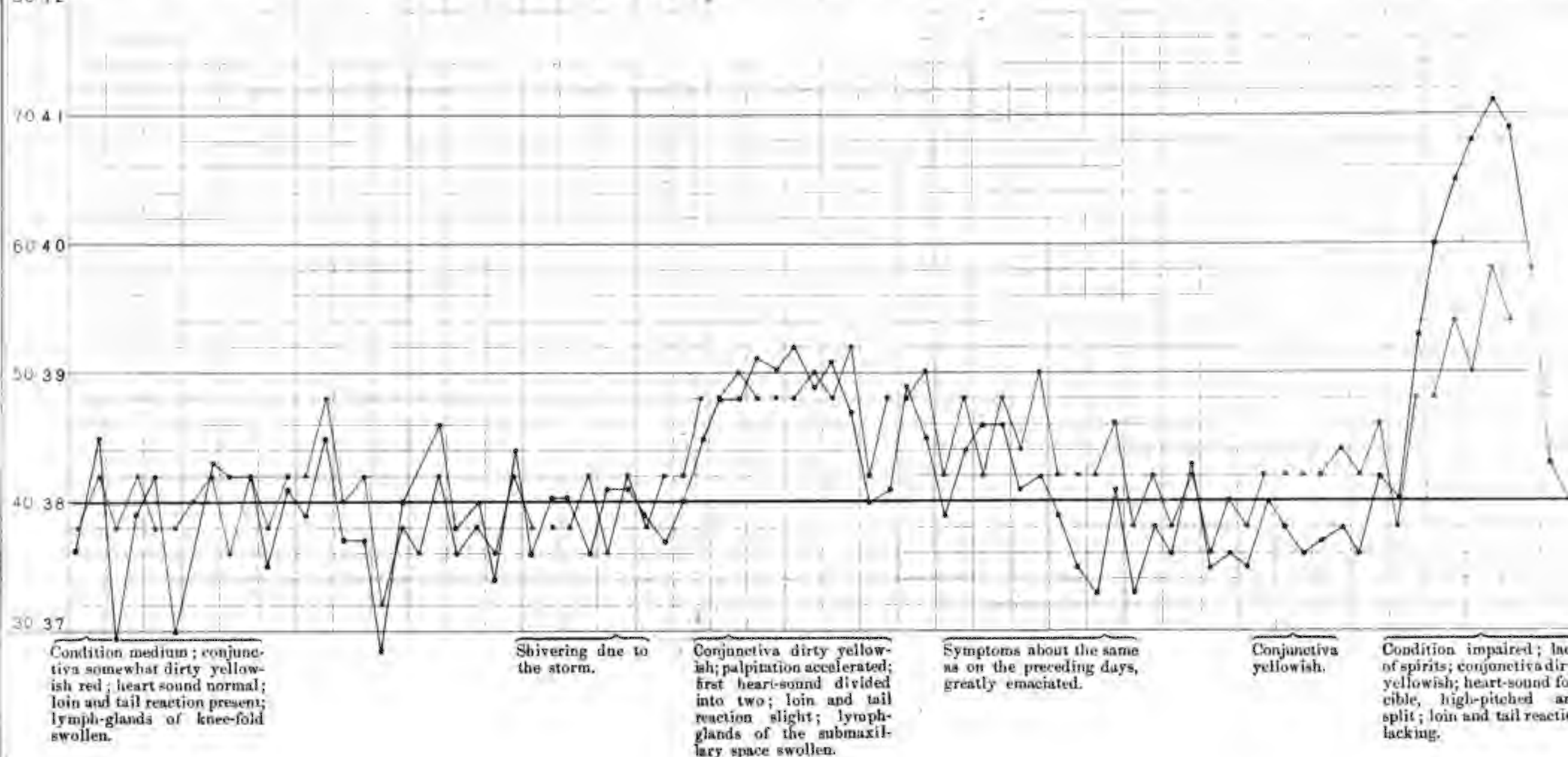

Remarks:-The subject was a heslthy horse. It was put under the care of the Comanttee as soon as it bad been diecharged from military atrics (1913), Experinent Station for the purpose of the experiment upon the transmission of the virus by the Hying insects. Towarda the latter part of June, its tempersture eurve part of August typical symptoms of infections unemia set in as is seen in the above ehart. 
Temperature and Pulse Curves of a Typical Case of Iniectious Anemia, Case II.

Experimental Horse No. 578, Age 18 Years.

(at the Izumi Experiment Station).-1913

Juily

August

Mu B⿺辶 12

60,39

- $0.3=$

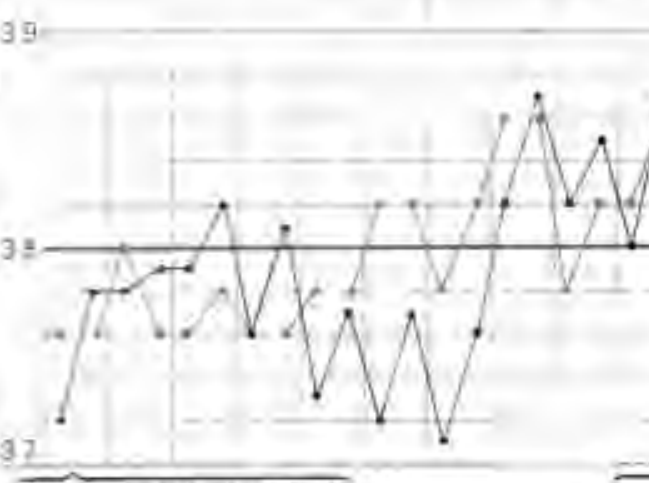

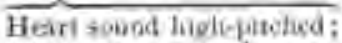

conjunctiva vorosd, pame: whac pale.

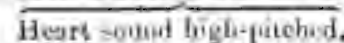

first soverd munled, second nplit; Iuck of apirite; no. tail reacive.
General oondicion bad muresur in the vecond heirt anast.
So appetic: lack of epirics: no loim and tail reaction; bigbly emaciated; conjunctivu pale; heart smond itrigolar; peteeliae on the nusal mucous membnne; ocderni

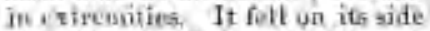
at 0.20 P.M., died it \$P.M.

Remarks:-The tolject was a licalphy horee $\mathrm{It}$ was put under the charge of the Commitice as soon as it had been diseharges from military

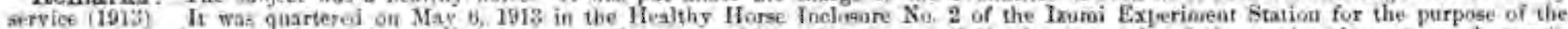

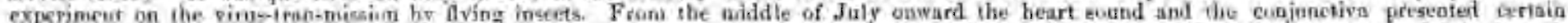

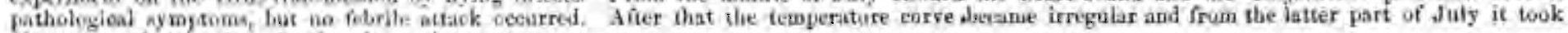
the course that in gives in the abuye chart. 


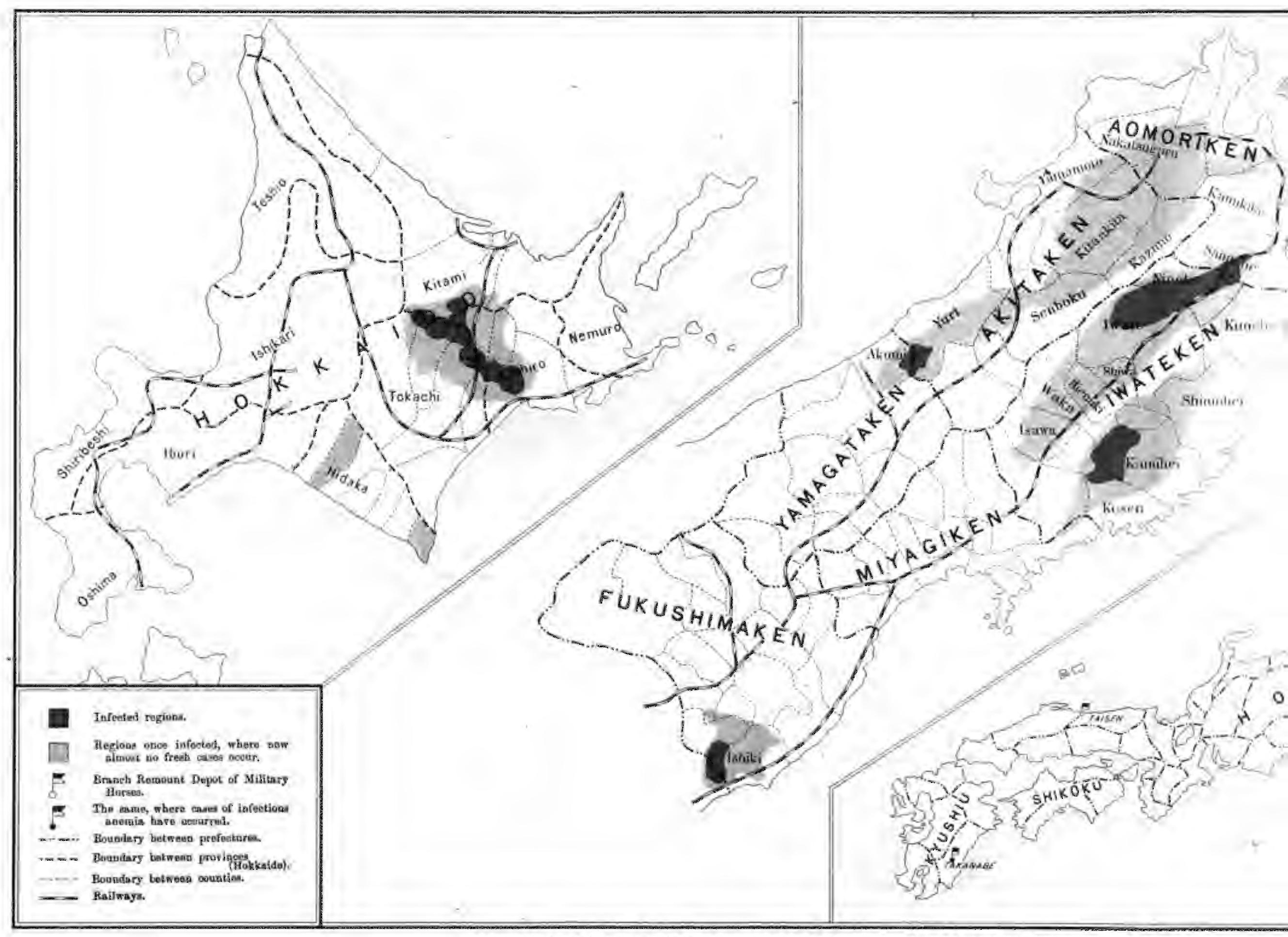

MAP SHOWING THE REGIONS INFECTED BY INFECTIOUS ANEMIA. 


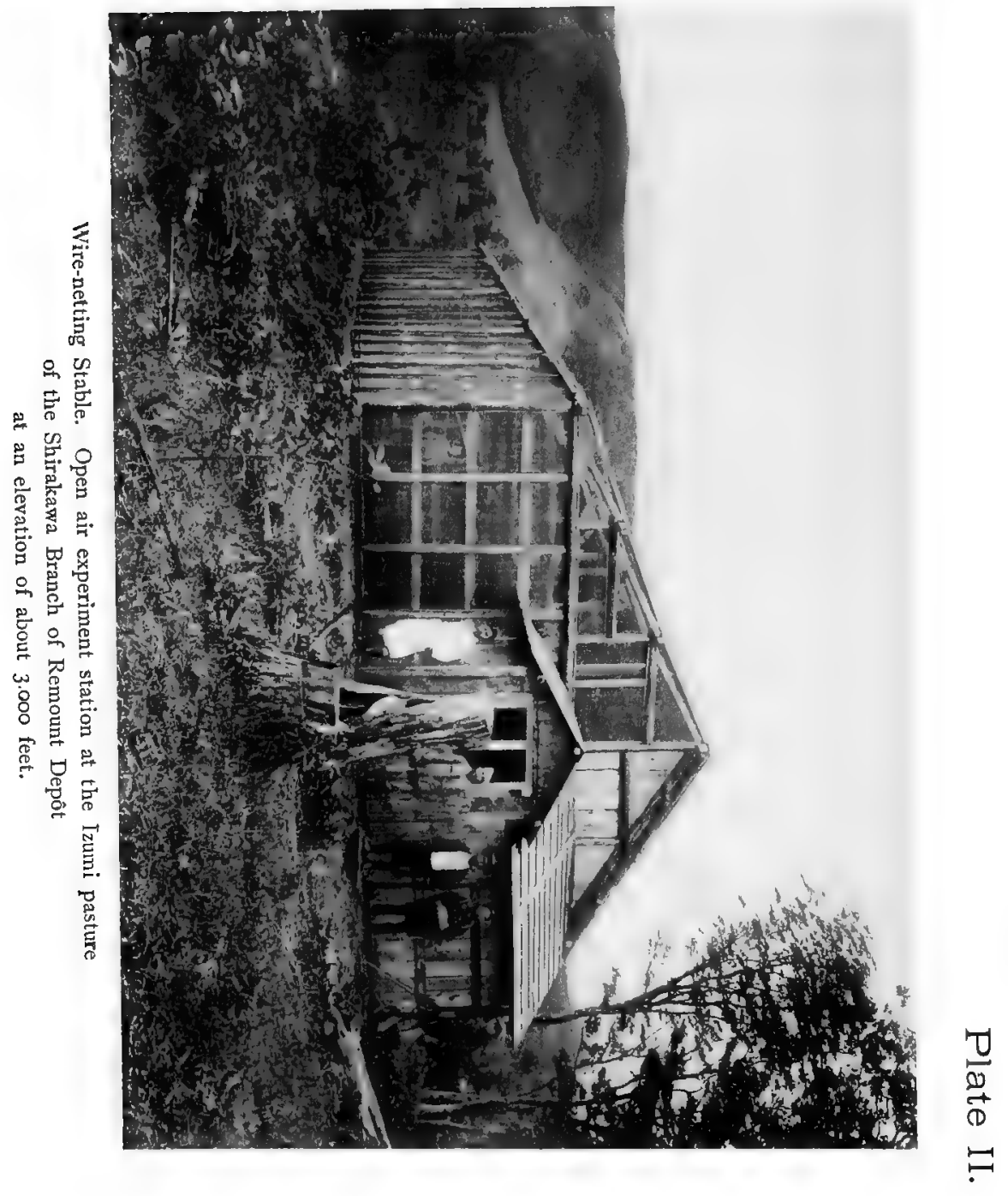





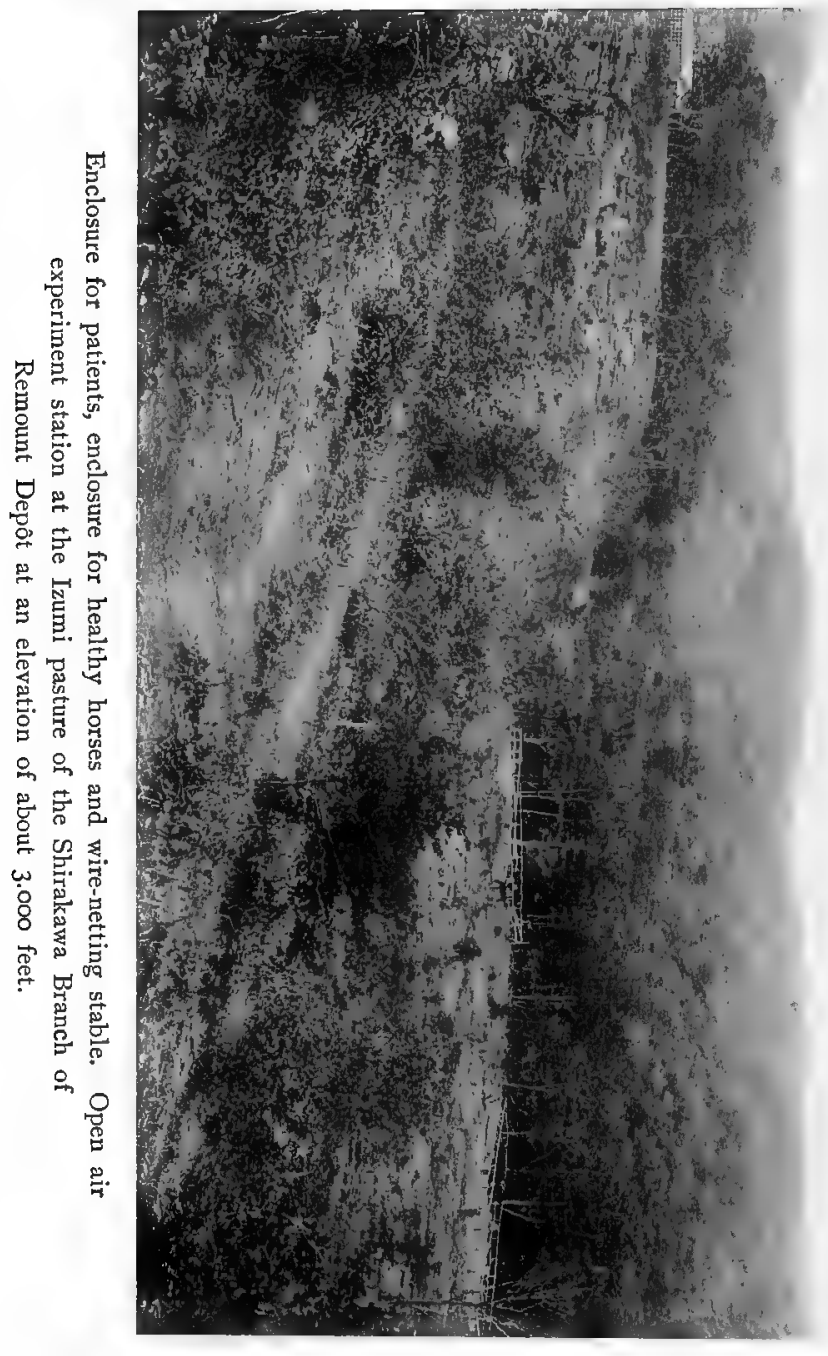





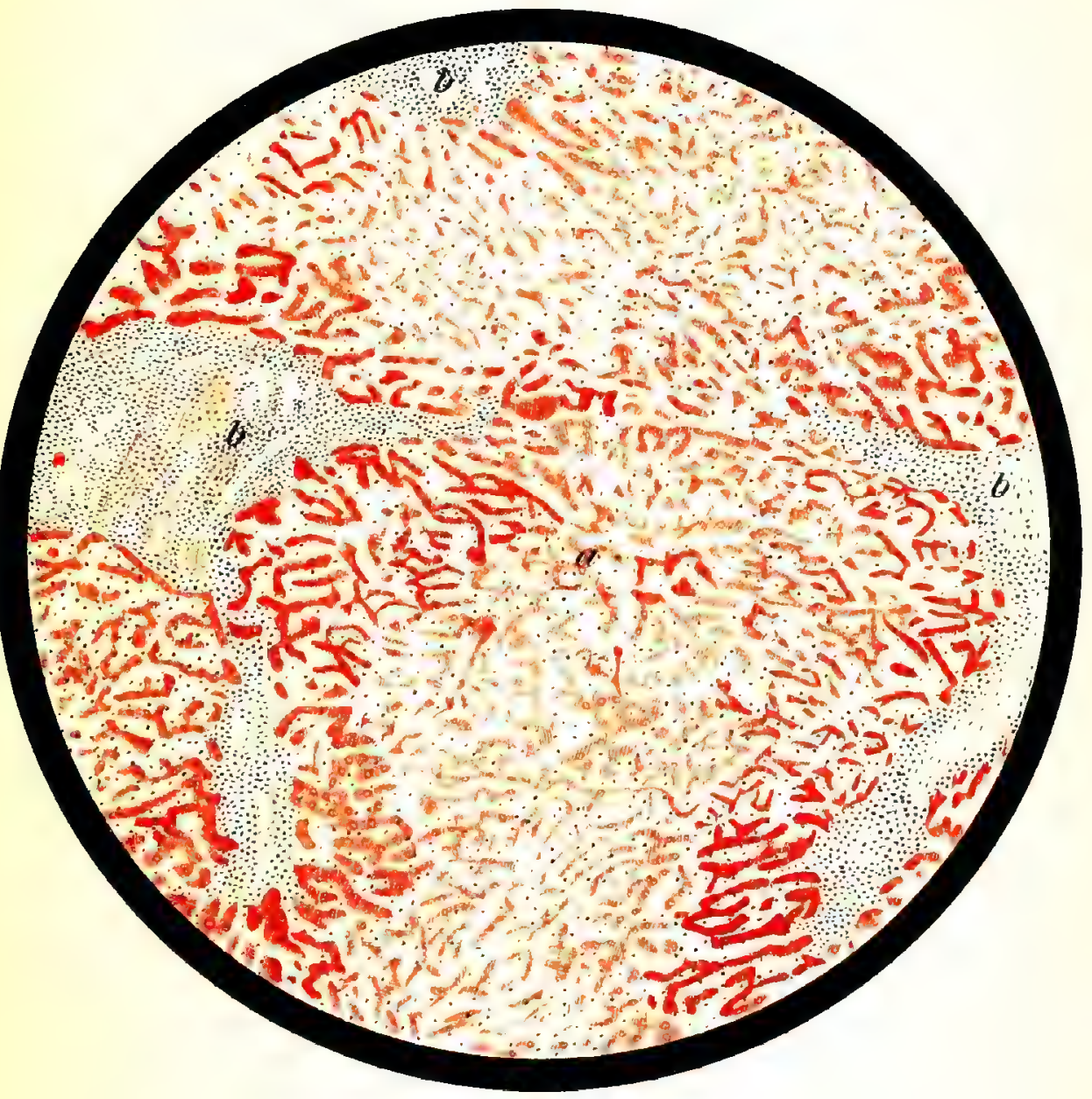

The small cell infiltration in lobule and interlobular connective tissue of the liber (coloured with hoematoxylin and eosin; magnified $\times$ 50). 


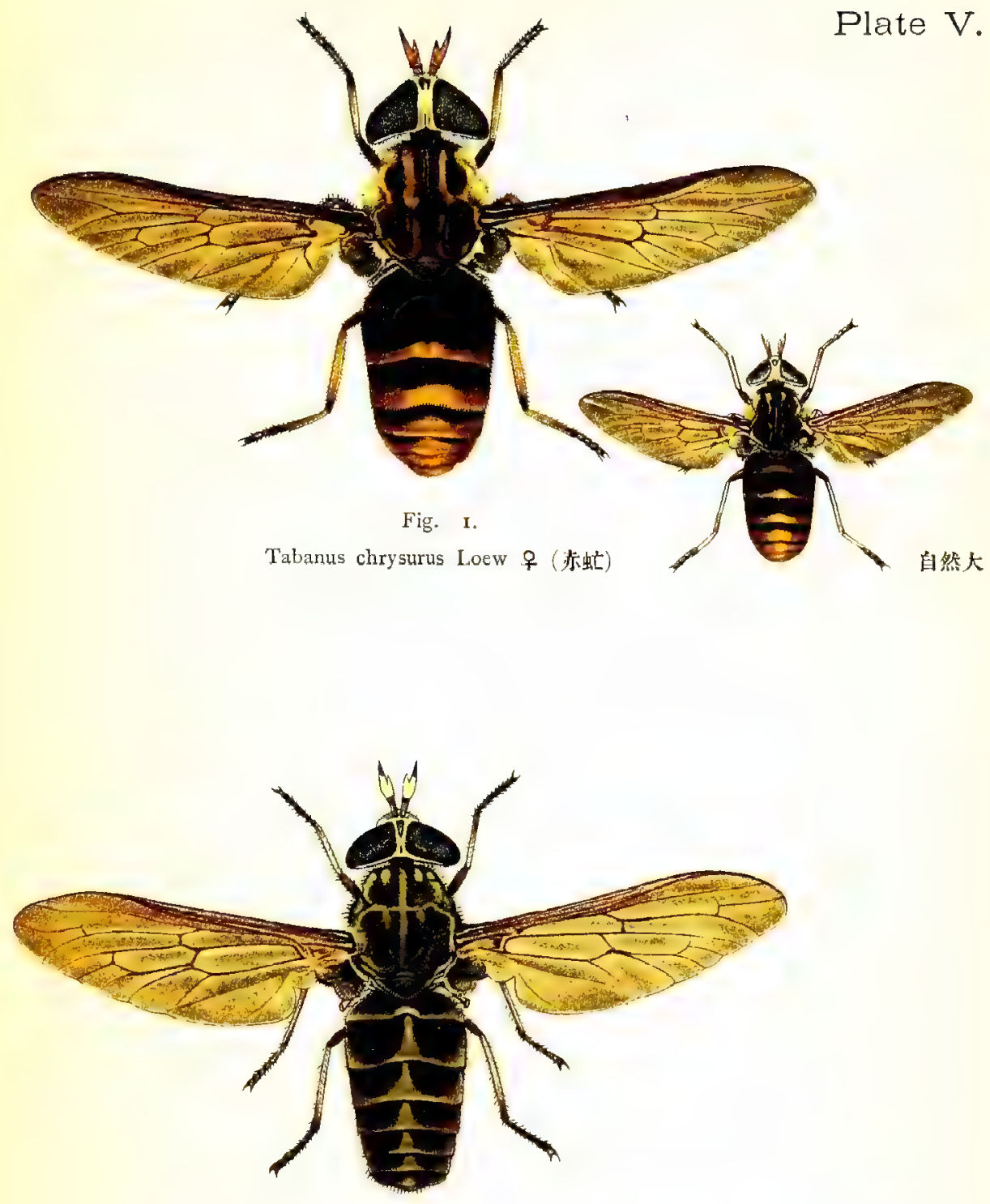

Fig. 2.

Tabanus trigonus Coq. 古 (青大虬)

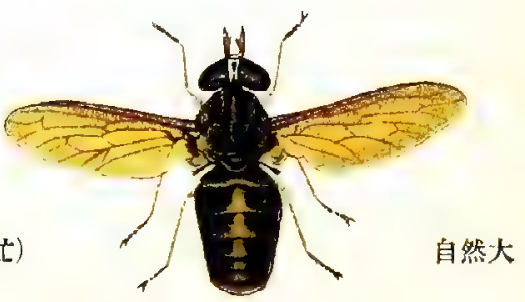





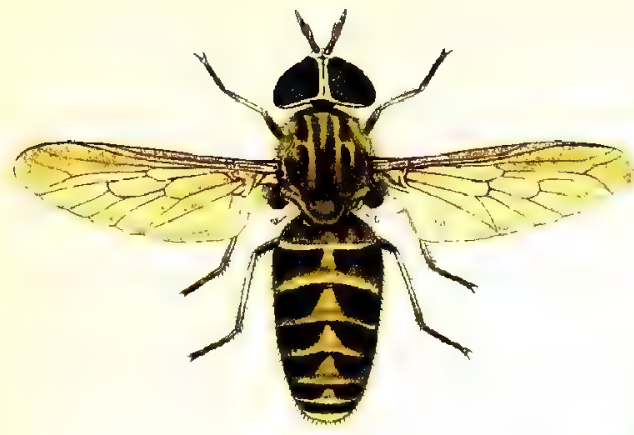

Fig. 3 .

Tabanus trigominus Coq. 早 (青中蛇)

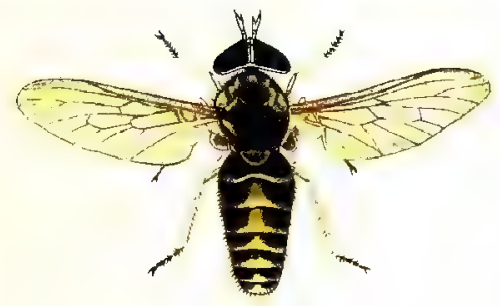

Fig. 4.

Tabanus turidus Fall. 우 (青小蚆)
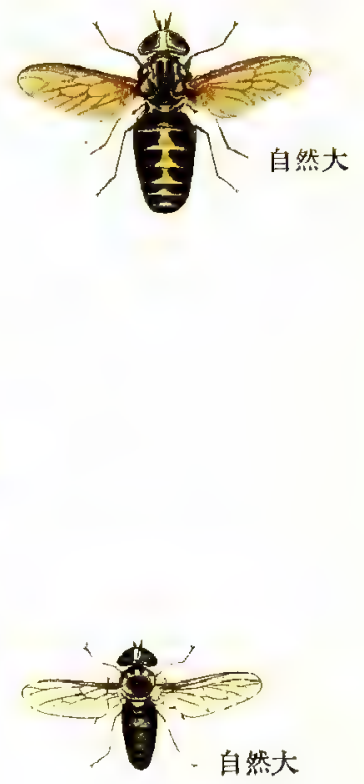

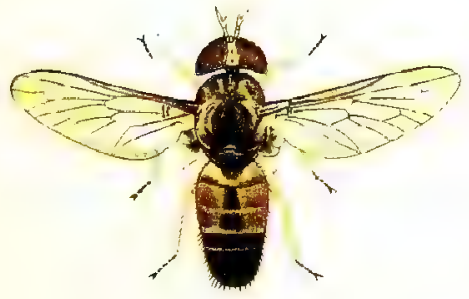

Fig. 5 .

Tabanus tropicus Meig. 우 (腹黄虬)

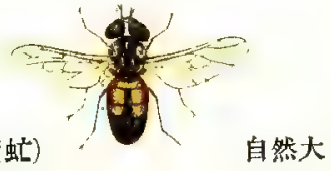





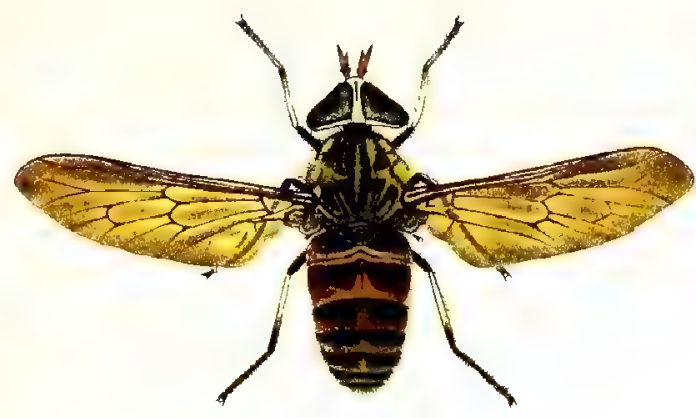

Fig. 6.

Tabanus rufidens Big. 우 (黄人虬)
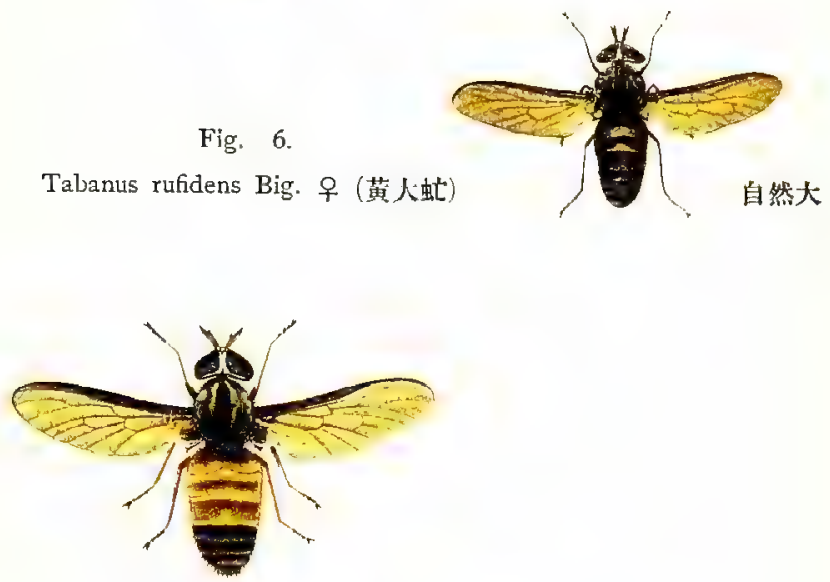

Fig. 7 .

Tabanus pyrauhus Walh. 우 (黄虬)
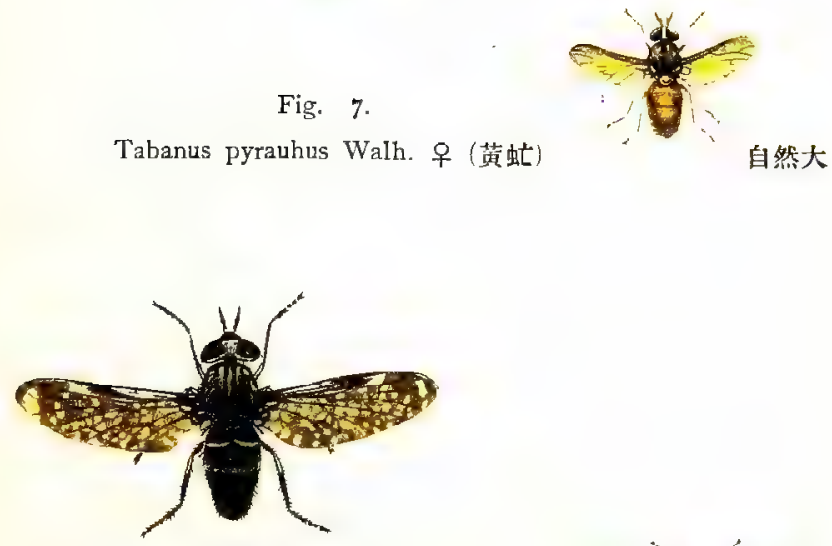

Fig. 8.

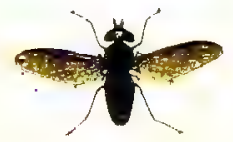

Homatopota tristis Big. 우 (䋗虬)

自然大 



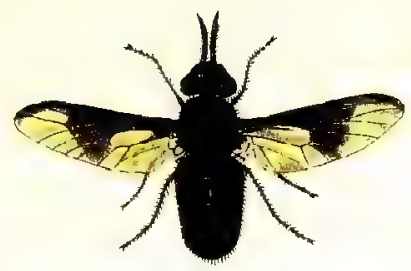

Fig. 9.

Chrysopus japonicus Wied. 우 (目虬)

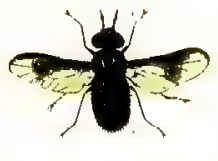

自然大

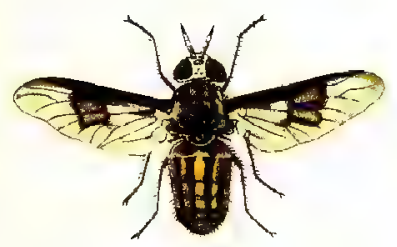

Fig. 10.

Chrysopus striatus Wulp. 우 (盲虬)
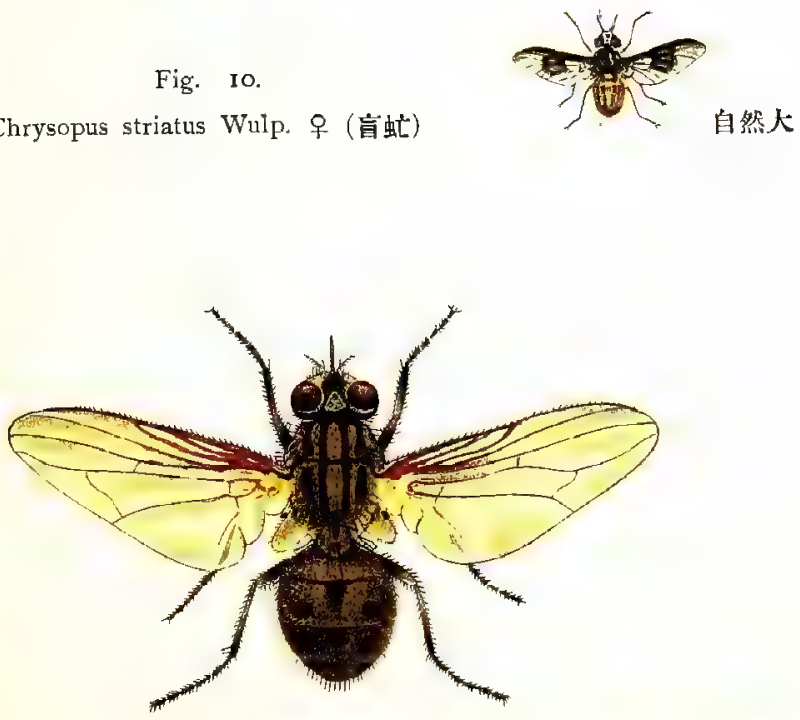

Fig. 11 .

Stomoxys calcitrans Linn. ㅇ (蟄蚆)

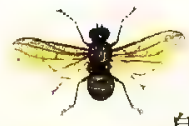

自然大 

$\frac{\dot{x}}{\stackrel{D}{a}}$

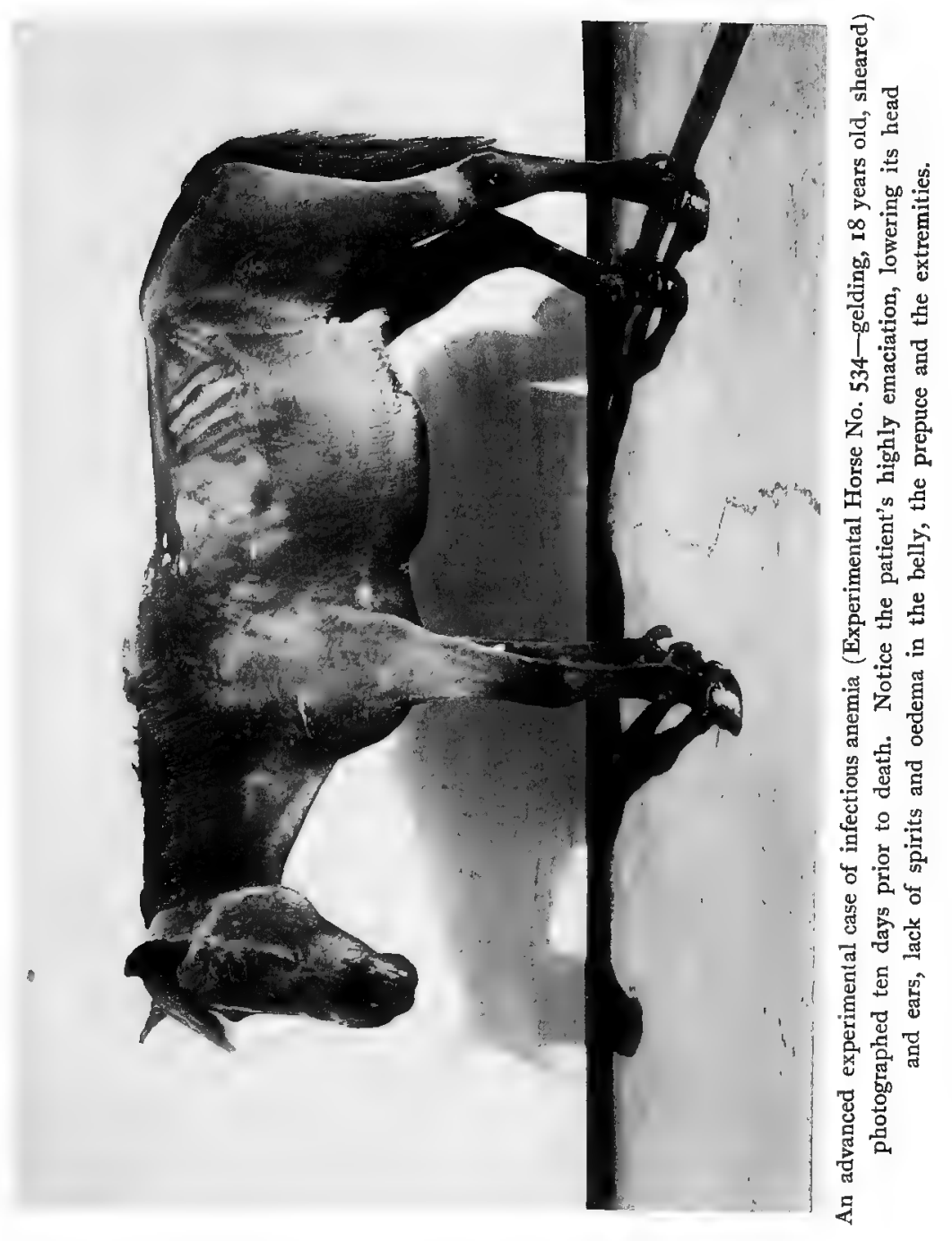







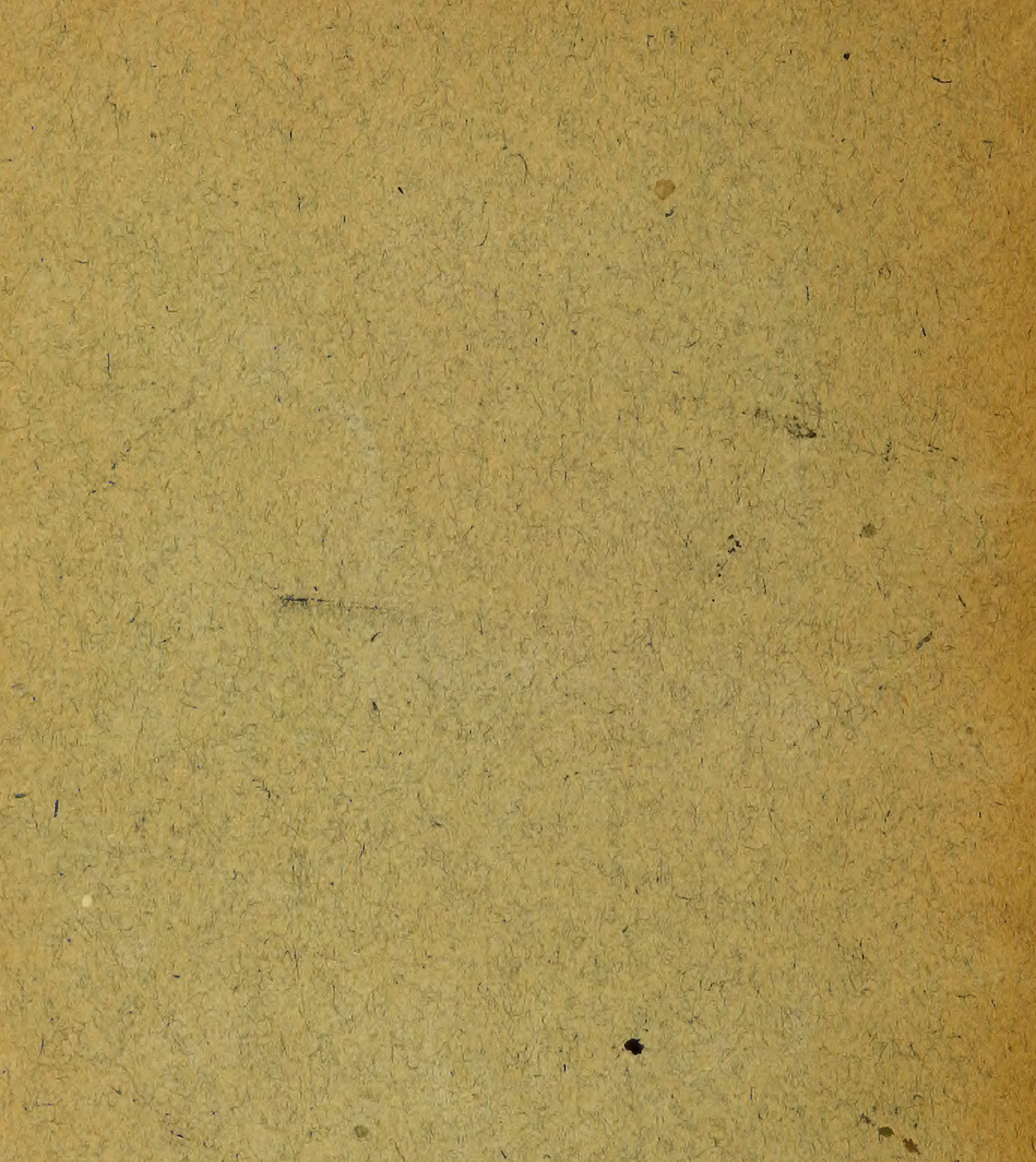